\title{
Hesitant triangular intuitionistic fuzzy information and its application to multi-attribute decision making problem
}

\author{
Jianjian Chen, Xianjiu Huang* \\ Department of Mathematics, Nanchang University, Nanchang, 330031, Jiangxi, P. R. China.
}

Communicated by S. Romaguera

\begin{abstract}
The concept of hesitant triangular intuitionistic fuzzy sets (HTIFSs) presented in this paper is based upon hesitant fuzzy sets and triangular intuitionistic fuzzy numbers (TIFNs). We have developed some hesitant triangular intuitionistic fuzzy aggregation operators and standardized hesitant triangular intuitionistic fuzzy aggregation operators. Inspired by Li et al. [D.-Q. Li, W.Y. Zeng, Y.-B. Zhao, Inform. Sci., 321 (2015), 103-115], the distance measures of hesitant triangular intuitionistic fuzzy sets are given, in order to explore the applications of which we have proposed three methods of multi-attribute decision making (MADM) problems, as well as analysis of the comparison between those methods, thus we give an example to illustrate these methods' applicability and availability. (C)2017 All rights reserved.
\end{abstract}

Keywords: Hesitant triangular intuitionistic fuzzy sets, operators, distance measure, multi-attribute decision making. 2010 MSC: 03E72, 03E75.

\section{Introduction}

It is hard for decision-makers to find an optimal choice that has the highest degree of satisfaction from a set of alternatives that are characterized in terms of their attributes in some situations, especially when relying on inaccurate, uncertain, or incomplete information. That is what are called MADM problems. So far, there have been two common methods for MADM problems. One way is to gather all the information related to the attributes in the multiple attribute decision making by aggregating operators and to rank the alternatives by the score function; the other way is to select the best alternative by calculating the distance measure between each alternative and the ideal one.

With information given by different environment, different aggregating operators have been proposed, which are being involved in different calculation processes for different decision making environment. In the research process of data information integration, the weighted averaging [4] operator, the ordered weighted averaging [20] operator, the weighted geometric [11] operator and the ordered weighted geometric $[5,18]$ operator are four common data aggregating operators. As the theory of fuzzy sets have been proposed by Zadeh [21], Atanassov [1,2] gave the concept of intuitionistic fuzzy set, after the intuitionistic fuzzy weighted averaging, intuitionistic fuzzy ordered weighted averaging, intuitionistic fuzzy

\footnotetext{
*Corresponding author

Email addresses: 18770084953@163.com (Jianjian Chen), xjhuangxwen@163.com (Xianjiu Huang)
} 
weighted geometric and intuitionistic fuzzy ordered weighted geometric operators were proposed, Torra $[12,13]$ introduced the concept of hesitant fuzzy set which permitted membership to have a set of possible values in order that the hesitant fuzzy set can reflect the human's hesitant behavior, after which Xia and $\mathrm{Xu}$ [16] proposed some operations of hesitant fuzzy set. And Zhao et al. [23] gave hesitant triangular fuzzy information and some aggregating operators like hesitant triangular fuzzy weighted averaging operator, hesitant triangular fuzzy ordered weighted averaging operator, hesitant triangular fuzzy weighted geometric operator, hesitant triangular fuzzy ordered weighted geometric operator to aggregate all the related information for MADM problems.

Distance measure, as an important topic in the fuzzy set theory that has been extensively applied in decision making, is an another method to deal with multi-attribute decision making and has attracted some researchers' interest. Many distance measures of fuzzy set [9], intuitionistic fuzzy set [17], intervalvalued fuzzy set [22] and interval-valued intuitionistic fuzzy set [10] have been proposed to solve decision making problems in place of operators, especially the Hamming distance, the Euclidean distance and the Hausdorff metric. Furthermore, $\mathrm{Xu}$ and $\mathrm{Xia}$ [19] first investigated distance measures of hesitant fuzzy sets. Then Li et al. $[7,8]$ provided some new distance measures on hesitant fuzzy sets which concluded the values and the number of values in order to overcome some drawbacks of existing distance measures. In addition, Wan et al. [14] gave the distance of TIFNs based on Hausdorff distance. However, For multiattribute decision making, distance measure must satisfy certain conditions, like the ideal alternative discussed earlier. Obviously, the aggregating operators are more extensive than the distance measures in multi-attribute decision making. And both the aggregation operators and the distance measures have to be built in a certain environment, such as intuitionistic fuzzy set, fuzzy environment and so on. In this paper, we give the hesitant triangular intuitionistic fuzzy set based on the hesitant fuzzy set and the triangular intuitionistic fuzzy numbers. Since the intuitionistic fuzzy set is a special case of the triangular intuitionistic fuzzy sets, and the hesitant triangular intuitionistic fuzzy set is the generalization of hesitant intuitionistic fuzzy sets, thus in many practical problems, the information provided by decision makers might hardly be described by intuitionistic fuzzy set. What the researchers could give is merely a set of real numbers on $R$ rather than an exact crisp degree of membership or non-membership. Under such circumstance, we make full use of the triangular intuitionistic fuzzy number and effectively overcome the difficulty. Meanwhile, the hesitant triangular intuitionistic fuzzy set is fit for the case when lots of decision makers provide the data like triangular intuitionistic fuzzy numbers. And inspired by the relative concepts of the aggregation operators and distance measures given by [8], three methods of the triangular intuitionistic fuzzy set are proposed to apply in MADM problems.

The remainder of the paper is organized as follows: In Section 2, we recall some basic concepts of hesitant sets and distance measures. In Section 3, new distance measures of triangular intuitionistic fuzzy numbers are given. In Section 4, we present the concepts of hesitant triangular intuitionistic fuzzy sets, and then we have developed some hesitant triangular intuitionistic fuzzy aggregation operators, standardized hesitant triangular intuitionistic fuzzy aggregation operators and the distance measures of hesitant triangular intuitionistic fuzzy sets. In Section 5, three methods to MADM problems with hesitant triangular intuitionistic fuzzy information are given based on Section 4. In Section 6, three methods of MADM problems, as well as the analysis of the comparison between these methods have been proposed to illustrate their applicability and availability by an example, and Section 7 comes to the conclusion of this paper.

\section{Preliminaries}

Throughout this paper, we use $X=\left\{x_{1}, x_{2}, \ldots x_{n}\right\}$ to denote the discourse set, TIFNs, HTIFS and HTIFE stand for triangular intuitionistic fuzzy numbers, hesitant triangular intuitionistic fuzzy set and hesitant triangular intuitionistic fuzzy element, respectively, $\mathrm{H}$ represents the set of hesitant triangular intuitionistic fuzzy elements on $X$, and $H(x)$ denotes the set of HTIFEs on $x$. 
Definition 2.1 ([12]). Let $X$ be a reference fixed set, and $E$ be an HFS given in terms of a function that will return a subset of $[0,1]$ when applied to $X$.

For convenience, the HFS is often expressed simply by mathematical symbol in Xia and Xu [16]:

$$
E=\left(<x, h_{E}(x)>\mid x \in X\right),
$$

where $h_{E}(x)$ is a set of some values in [0,1], denoting the possible membership degree of the element $x \in X$ to the set $E$. The variable $h_{E}(x)$ is denoted as a hesitant fuzzy element.

Definition 2.2 ([16]). For a HFE $h, s(h)=\frac{1}{\# h} \sum_{\gamma \in h} \gamma$ is called the score function of $h$, where \#h is the number of the elements in $h$. For two HFEs $h_{1}$ and $h_{2}$, if $s\left(h_{1}\right)>s\left(h_{2}\right)$, then $h_{1}>h_{2} ;$ if $s\left(h_{1}\right)=s\left(h_{2}\right)$, then $h_{1}=h_{2}$.

Xu and Xia [16] also defined some operations on the HFEs $h, h_{1}$, and $h_{2}$ :

(1) $h_{\lambda}=\cup_{\gamma \in h}\left\{\gamma^{\lambda}\right\}$;

(2) $\lambda \mathrm{h}=\cup_{\gamma \in \mathrm{h}}\left\{1-(1-\gamma)^{\lambda}\right\}$;

(3) $h_{1} \oplus h_{2}=\cup_{\gamma_{1} \in h_{1}, \gamma_{2} \in h_{2}}\left\{\gamma_{1}+\gamma_{2}-\gamma_{1} \gamma_{2}\right\}$;

(4) $h_{1} \otimes h_{2}=\cup_{\gamma_{1} \in h_{1}, \gamma_{2} \in h_{2}}\left\{\gamma_{1} \gamma_{2}\right\}$.

Definition 2.3 ([19]). Let $M$ and $N$ be two hesitant fuzzy sets on $X$, then the distance measure between $M$ and $\mathrm{N}$ is defined as which satisfies the following properties:

(i) $0 \leqslant d(M, N) \leqslant 1$;

(ii) $d(M, N)=0$ if and only if $M=N$;

(iii) $d(M, N)=d(N, M)$.

Notice that the number of elements in different hesitant fuzzy elements may be different. To operate correctly, $\mathrm{Xu}$ and $\mathrm{Xia}$ [19] gave the following regulation: the shorter one is extended by adding the minimum value, the maximum value, or any value in it until it has the same length with the longer one. And Li et al. [8] extended the shorter one by adding the minimum value and proposed the concepts of distance measures considering hesitance degree.

Definition 2.4 ([8]). Let $M$ be a hesitant fuzzy set on $X=\left\{x_{1}, x_{2}, \ldots x_{n}\right\}$, and for any $x_{i} \in X, l\left(h_{M}\left(x_{i}\right)\right)$ be the length of $h_{M}\left(x_{i}\right)$. Denote

$$
\begin{aligned}
u\left(h_{M}\left(x_{i}\right)\right) & =1-\frac{1}{l\left(h_{M}\left(x_{i}\right)\right)}, \\
u(M) & =\frac{1}{n} \sum_{i=1}^{n} u\left(h_{M}\left(x_{i}\right)\right),
\end{aligned}
$$

we call $u\left(h_{M}\left(x_{i}\right)\right)$ the hesitance degree of $h_{M}\left(x_{i}\right)$, and $u(M)$ the hesitance degree of $M$.

Definition 2.5 ([8]). Let $\left\{M_{1}, M_{2}, \ldots, M_{m}\right\}$ be a set of HFS on $X=\left\{x_{1}, x_{2}, \ldots, x_{n}\right\}$, then for any $M_{k}$ and $M_{t}$, $k, t=1,2, \ldots, m$, the normalized Hamming distance including hesitance degree between $M_{k}$ and $M_{t}$ is defined as

$$
d_{h u h}\left(M_{k}, M_{t}\right)=\frac{1}{2 n} \sum_{i=1}^{n}\left[\left|u\left(h_{M_{k}}\left(x_{i}\right)\right)-u\left(h_{M_{t}}\left(x_{i}\right)\right)\right|+\frac{1}{l_{x_{i}}} \sum_{j=1}^{l_{x_{i}}}\left|h_{M_{k}}^{\sigma(j)}\left(x_{i}\right)-h_{M_{t}}^{\sigma(j)}\left(x_{i}\right)\right|\right] .
$$

The normalized Euclidean distance including hesitance degree between $M_{k}$ and $M_{t}$ is defined as

$$
d_{h u e}\left(M_{k}, M_{t}\right)=\left[\frac{1}{2 n} \sum_{i=1}^{n}\left(\left|u\left(h_{M_{k}}\left(x_{i}\right)\right)-u\left(h_{M_{t}}\left(x_{i}\right)\right)\right|^{2}+\frac{1}{4 l_{x_{i}}} \sum_{j=1}^{l_{x_{i}}}\left|h_{M_{k}}^{\sigma(j)}\left(x_{i}\right)-h_{M_{t}}^{\sigma(j)}\left(x_{i}\right)\right|^{2}\right)\right]^{1 / 2} .
$$


The normalized generalized distance including hesitance degree between $M_{k}$ and $M_{t}$ is defined as

$$
d_{\text {hug }}\left(M_{k}, M_{t}\right)=\left[\frac{1}{2 n} \sum_{i=1}^{n}\left(\left|u\left(h_{M_{k}}\left(x_{i}\right)\right)-u\left(h_{M_{t}}\left(x_{i}\right)\right)\right|^{\lambda}+\frac{1}{4 l_{x_{i}}} \sum_{j=1}^{l_{x_{i}}}\left|h_{M_{k}}^{\sigma(j)}\left(x_{i}\right)-h_{M_{t}}^{\sigma(j)}\left(x_{i}\right)\right|^{\lambda}\right)\right]^{1 / \lambda},
$$

where $\lambda>1$ and $h_{M_{k}}^{j}\left(x_{i}\right)$ and $h_{M_{t}}^{j}\left(x_{i}\right)$ are the $j$ th values in $h_{M_{k}}\left(x_{i}\right)$ and $h_{M_{t}}\left(x_{i}\right)$, respectively, and $l_{x_{i}}=\max _{\mathbf{q} \in \mathrm{I}}\left\{l\left(h_{\mathbf{q}}\left(x_{i}\right)\right)\right\}, I=\{1,2, \ldots, m\}$.

\section{Distance measure of triangular intuitionistic fuzzy numbers}

\subsection{The definition and operations of TIFNs}

Definition 3.1 ([3]). A TIFN $\tilde{a}=\left((\underline{a}, a, \bar{a}) ; \omega_{\tilde{a}}, u_{\tilde{a}}\right)$ is a special IFS on the set $R$ of real numbers, whose membership function and non-membership function are defined as follows:

$$
\mu_{\tilde{a}}(x)= \begin{cases}\frac{x-a}{\bar{a}-\overline{\bar{a}}} \omega_{\tilde{a}}, & \text { if } \underline{a} \leqslant x<a, \\ \omega_{\tilde{a}}, & \text { if } x=a, \\ \frac{\bar{a}-x}{\bar{a}-a} \omega_{\tilde{a}}, & \text { if } a<x \leqslant \bar{a}, \\ 0, & \text { if } x<\underline{a} \text { or } x>\bar{a}\end{cases}
$$

and

$$
v_{\tilde{a}}(x)= \begin{cases}\frac{a-x+(x-\underline{a}) u_{\tilde{a}}}{a-\bar{a}}, & \text { if } \underline{a} \leqslant x<a, \\ u_{\tilde{a}}, & \text { if } x=a, \\ \frac{x-a+(\underline{a}-x) u_{\tilde{a}}}{\bar{a}-a}, & \text { if } a<x \leqslant \bar{a}, \\ 1, & \text { if } x<\underline{a} \text { or } x>\bar{a},\end{cases}
$$

respectively. The values $\omega_{\tilde{a}}$ and $u_{\tilde{a}}$ represent the maximum degree of membership and the minimum degree of nonmembership, respectively, such that they satisfy the conditions $0 \leqslant \omega_{\tilde{a}} \leqslant 1,0 \leqslant u_{\tilde{a}} \leqslant 1$, and $0 \leqslant \omega_{\tilde{a}}+u_{\tilde{a}} \leqslant 1, \underline{a}, a, \bar{a} \in R$.

Let

$$
\pi_{\tilde{\mathbf{a}}}(x)=1-\mu_{\tilde{\mathbf{a}}}(x)-v_{\tilde{\mathbf{a}}}(x),
$$

which is called an intuitionistic fuzzy index of an element $x$ in $\tilde{a}$. It is the degree of the indeterminacy membership of the element $x$ in $\tilde{a}$. [6]:

The used arithmetical operations over triangular intuitionistic fuzzy numbers may be shown as follows

Definition $3.2([6])$. Let $\tilde{a}=\left((\underline{a}, a, \bar{a}) ; \omega_{\tilde{a}}, u_{\tilde{a}}\right)$ and $\tilde{b}=\left((\underline{b}, b, \bar{b}) ; \omega_{\tilde{b}}, u_{\tilde{b}}\right)$ be two TIFNs and $\lambda$ be a real number. The arithmetical operations are stipulated as follows:

$$
\begin{aligned}
& \tilde{\mathrm{a}} \pm \tilde{\mathrm{b}}=\left((\underline{\mathrm{a}} \pm \underline{\mathrm{b}}, \mathrm{a} \pm \mathrm{b}, \overline{\mathrm{a}} \pm \overline{\mathrm{b}}) ; \min \left\{\omega_{\tilde{\mathrm{a}}}, \omega_{\tilde{\mathrm{b}}}\right\}, \max \left\{\mathrm{u}_{\tilde{\mathrm{a}}}, \mathrm{u}_{\tilde{\mathrm{b}}}\right\}\right), \\
& \tilde{a} \tilde{b}= \begin{cases}\left((\underline{a b}, a b, \bar{a} \bar{b}) ; \min \left\{\omega_{\tilde{a}}, \omega_{\tilde{b}}\right\}, \max \left\{u_{\tilde{a}}, u_{\tilde{b}}\right\}\right), & \text { if } \tilde{a}>0 \text { and } \tilde{b}>0, \\
\left((\underline{a} \bar{b}, a b, \bar{a} \underline{b}) ; \min \left\{\omega_{\tilde{a}}, \omega_{\tilde{b}}\right\}, \max \left\{u_{\tilde{a}}, u_{\tilde{b}}\right\}\right), & \text { if } \tilde{a}<0 \text { and } \tilde{b}>0, \\
\left((\bar{a} \bar{b}, a b, \underline{a b}) ; \min \left\{\omega_{\tilde{a}}, \omega_{\tilde{b}}\right\}, \max \left\{u_{\tilde{a}}, u_{\tilde{b}}\right\}\right), & \text { if } \tilde{a}<0 \text { and } \tilde{b}<0,\end{cases} \\
& \tilde{a} / \tilde{b}= \begin{cases}\left((\underline{a} / \bar{b}, a / b, \bar{a} / \underline{b}) ; \min \left\{\omega_{\tilde{a}}, \omega_{\tilde{b}}\right\}, \max \left\{u_{\tilde{a}}, u_{\tilde{b}}\right\}\right), & \text { if } \tilde{a}>0 \text { and } \tilde{b}>0, \\
\left((\bar{a} / \bar{b}, a / b, \underline{a} / \underline{b}) ; \min \left\{\omega_{\tilde{a}}, \omega_{\tilde{b}}\right\}, \max \left\{u_{\tilde{a}}, u_{\tilde{b}}\right\}\right), & \text { if } \tilde{a}<0 \text { and } \tilde{b}>0, \\
\left((\bar{a} / \underline{b}, a / b, \underline{a} / \bar{b}) ; \min \left\{\omega_{\tilde{a}}, \omega_{\tilde{b}}\right\}, \max \left\{u_{\tilde{a}}, u_{\tilde{b}}\right\}\right), & \text { if } \tilde{a}<0 \text { and } \tilde{b}<0,\end{cases} \\
& \lambda \tilde{a}= \begin{cases}\left((\lambda \underline{a}, \lambda a, \lambda \bar{a}) ; \omega_{\tilde{a}}, u_{\tilde{a}}\right), & \text { if } \lambda>0, \\
\left((\lambda \bar{a}, \lambda a, \lambda \underline{a}) ; \omega_{\tilde{a}}, u_{\tilde{a}}\right), & \text { if } \lambda<0,\end{cases} \\
& \tilde{\mathrm{a}}^{-1}=\left((1 / \overline{\mathrm{a}}, 1 / \mathrm{a}, 1 / \underline{\mathrm{a}}) ; \omega_{\tilde{\mathrm{a}}}, \mathrm{u}_{\tilde{\mathrm{a}}}\right) \text {. }
\end{aligned}
$$


It is proven that the results from multiplication and division are not TIFNs. But we always use TIFNs to express these operational results approximately.

\subsection{The distance of TIFNs}

In [14], the values of the membership function $\mu_{\tilde{a}}(x)$ and the non-membership function $v_{\tilde{a}}(x)$ for the TIFN $\tilde{a}=\left((\underline{a}, a, \bar{a}) ; \omega_{\tilde{a}}, u_{\tilde{a}}\right)$ are calculated as follows:

$$
\begin{aligned}
& V_{\mu}(\tilde{a})=\frac{(\underline{a}+4 a+\bar{a}) \omega_{\tilde{a}}}{6}, \\
& V_{v}(\tilde{a})=\frac{(\underline{a}+4 a+\bar{a})\left(1-\mu_{\tilde{a}}\right)}{6},
\end{aligned}
$$

respectively.

At the same time, the ambiguities of the membership function $\mu_{\tilde{a}}(x)$ and the non-membership function $v_{\tilde{a}}(x)$ for the TIFN $\tilde{a}=\left((\underline{a}, a, \bar{a}) ; \omega_{\tilde{a}}, u_{\tilde{a}}\right)$ are calculated as follows:

$$
\begin{aligned}
& A_{\mu}(\tilde{a})=\frac{(\bar{a}-\underline{a}) \omega_{\tilde{a}}}{3} \\
& A_{\nu}(\tilde{a})=\frac{(\bar{a}-\underline{a})\left(1-\mu_{\tilde{a}}\right)}{3},
\end{aligned}
$$

respectively.

Based on the values and ambiguities of TIFNs, we give the following definition.

Definition 3.3. Let $\tilde{a}=\left((\underline{a}, a, \bar{a}) ; w_{1}, u_{1}\right)$ and $\tilde{b}=\left((\underline{b}, b, \bar{b}) ; w_{2}, u_{2}\right)$ be two TIFNs. The distance between them is defined as follows:

$$
d_{h}(\tilde{a}, \tilde{b})=\frac{1}{2}\left[\lambda\left(\left|V_{\mu}(\tilde{\mathfrak{a}})^{*}-V_{\mu}(\tilde{\mathfrak{b}})^{*}\right|+\left|V_{v}(\tilde{\mathfrak{a}})^{*}-V_{v}(\tilde{\mathfrak{b}})^{*}\right|\right)+(1-\lambda)\left(\left|A_{\mu}(\tilde{\mathfrak{a}})^{*}-A_{\mu}(\tilde{\mathbf{b}})^{*}\right|+\left|A_{v}(\tilde{\mathbf{a}})^{*}-A_{v}(\tilde{\mathbf{b}})^{*}\right|\right)\right],
$$

where $V_{\mu}(\tilde{\mathbf{a}})^{*}=\frac{(\underline{a}+4 a+\bar{a}) \omega_{\tilde{a}}}{6 a^{*}}, V_{\mu}(\tilde{b})^{*}=\frac{(\underline{b}+4 b+\bar{b}) \omega_{\tilde{b}}}{6 b^{*}}, V_{v}(\tilde{a})^{*}=\frac{(\underline{a}+4 a+\bar{a})\left(1-\mu_{\tilde{a}}\right)}{6 a^{*}}, V_{v}(\tilde{b})^{*}=\frac{(\underline{b}+4 b+\bar{b})\left(1-\mu_{\tilde{b}}\right)}{6 b^{*}}$, $A_{\mu}(\tilde{a})^{*}=\frac{(\bar{a}-\underline{a}) \omega_{\tilde{a}}}{3 a^{*}}, A_{\mu}(\tilde{b})^{*}=\frac{(\bar{b}-\underline{b}) \omega_{\tilde{b}}}{3 b^{*}}, A_{\gamma}(\tilde{a})^{*}=\frac{(\bar{a}-\underline{a})\left(1-\mu_{\tilde{a}}\right)}{3 a^{*}}, A_{\gamma}(\tilde{b})^{*}=\frac{(\bar{b}-\underline{b})\left(1-\mu_{\tilde{b}}\right)}{3 b^{*}}$, and $0 \leqslant \lambda \leqslant 1 . a^{*}$ and $b^{*}$ are standardized constants.

Remark 3.4. The values of $\mathrm{a}^{*}$ and $\mathrm{b}^{*}$ depend on the requirement of environment. It concludes two cases: (1) the two numbers' distance of TIFNs $\tilde{a}_{i}=\left(\left(\underline{a}_{i}, a_{i}, \bar{a}_{i}\right) ; w_{i}, u_{i}\right)$ without any scene: $a^{*}=b^{*}=\max \left\{\bar{a}_{i}\right\}$;

(2) the $a^{*}$ of TIFNs can be embodied in the specific environment and satisfy the condition $a^{*} \geqslant \max \left\{\bar{a}_{i}\right\}$, such as the following example.

Example 3.5. In the final assessment of a class, the distribution of the final examination results of all the students is a TIFN $\tilde{a}=((50,70,80), 0.6,0.3)$, the total score is 100 , and the students in the class of the usual performance is the TIFN $\tilde{b}=((5,7,8), 0.6,0.3)$, the total scores is 10 . Then we have $a^{*}=100, b^{*}=10$, and

$$
\mathrm{d}_{\mathrm{h}}(\tilde{\mathrm{a}}, \tilde{\mathrm{b}})=\mathrm{d}_{\mathrm{e}}(\tilde{\mathrm{a}}, \tilde{\mathrm{b}})=0,
$$

so the final examination results are consistent with the usual performance. This conclusion is apparent in line with the reality.

Remark 3.6. The distance contains both values and ambiguities of TIFNs, and the preferences between values and ambiguities depends on the value $\lambda$. When we only consider values of TIFNs $(\lambda=0)$, $\mathrm{d}_{\mathrm{h}}(\tilde{\mathrm{a}}, \tilde{\mathrm{b}})=\lambda\left(\left|\mathrm{V}_{\mu}(\tilde{\mathrm{a}})-\mathrm{V}_{\mu}(\tilde{\mathrm{b}})\right|+\left|\mathrm{V}_{v}(\tilde{\mathrm{a}})-\mathrm{V}_{v}(\tilde{\mathrm{b}})\right|\right)$

Definition 3.7. For a TIFN $\tilde{a}, s(\tilde{a})=\frac{(\underline{a}+2 a+\bar{a})\left(\omega_{\tilde{a}}-u_{\tilde{a}}\right)}{4 a^{*}}$ and $h(\tilde{a})=\frac{(\underline{a}+2 a+\bar{a})\left(\omega_{\tilde{a}}+\mathfrak{u}_{\tilde{a}}\right)}{4 a^{*}}$ are called the score function and the accuracy function of $\tilde{a}$, respectively, where $a^{*}$ is a standardized constant. 
For two TIFNs $\tilde{\mathrm{a}}_{1}$ and $\tilde{\mathrm{a}}_{2}$,

- if $\mathrm{s}\left(\tilde{\mathrm{a}}_{1}\right)>\mathrm{s}\left(\tilde{\mathrm{a}}_{2}\right)$, then $\tilde{\mathrm{a}}_{1} \succ \tilde{\mathrm{a}}_{2}$;

- if $\mathrm{s}\left(\tilde{\mathrm{a}}_{1}\right)<\mathrm{s}\left(\tilde{\mathrm{a}}_{2}\right)$, then $\tilde{\mathrm{a}}_{1} \prec \tilde{\mathrm{a}}_{2}$;

- if $s\left(\tilde{\mathrm{a}}_{1}\right)=s\left(\tilde{\mathrm{a}}_{2}\right)$ and

$* h\left(\tilde{\mathrm{a}}_{1}\right)>\mathrm{h}\left(\tilde{\mathrm{a}}_{2}\right)$, then $\tilde{\mathrm{a}}_{1} \succ \tilde{\mathrm{a}}_{2} ;$

$* h\left(\tilde{a}_{1}\right)<h\left(\tilde{a}_{2}\right)$, then $\tilde{a}_{1} \prec \tilde{a}_{2} ;$

$* h\left(\tilde{\mathrm{a}}_{1}\right)=\mathrm{h}\left(\tilde{\mathrm{a}}_{2}\right)$, then $\tilde{\mathrm{a}}_{1}=\tilde{\mathrm{a}}_{2}$.

So we can compare two score functions and judge the magnitudes of two TIFNs.

\section{Hesitant triangular intuitionistic fuzzy information}

\subsection{Hesitant triangular intuitionistic fuzzy sets}

As can be seen from Definition 2.1, hesitant fuzzy set expresses the membership degrees of an element to a given set only by several real numbers between 0 and 1 , while in many real-world situations assigning exact values to the membership degrees do not describe properly the imprecise or uncertain decision information. Thus, it seems to be difficult for the decision makers to rely on hesitant fuzzy sets for expressing uncertainty of an element.

To overcome the difficulty associated with expressing uncertainty of an element to a given set, the concept of hesitant triangular intuitionistic fuzzy set is introduced here to let decision makers provide the data like triangular intuitionistic fuzzy numbers based on the concepts of hesitant fuzzy sets and triangular intuitionistic fuzzy numbers.

Definition 4.1. Given a fixed set $X$, a hesitant triangular intuitionistic fuzzy set (HTIFS) on $X$ is in terms of a function that is applied to each $x$ in $X$ and returns a set of some possible triangular intuitionistic fuzzy numbers.

To be easily understood, we express the HTIFS by a mathematical symbol:

$$
E=\left\{<x, \tilde{h}_{E}^{\prime}(x)>\mid x \in X\right\},
$$

where $\tilde{h}_{E}^{\prime}(x)$ is a set of some possible triangular intuitionistic fuzzy numbers, denoting the possible membership degrees of the element $x \in X$ to the set $E$. For convenience, we call $\tilde{h}_{E}^{\prime}(x)=\bigcup_{i}\left(\left(\underline{a}_{i}, a_{i}, \bar{a}_{i}\right) ; \omega_{i}, u_{i}\right)(i=$ $\left.1,2, \ldots, l\left(\tilde{h}^{\prime}\right)\right)$ a hesitant triangular intuitionistic fuzzy element (HTIFE) $\left(l\left(\tilde{h}^{\prime}\right)\right.$ is the length of HTIFE) and $E$ the set of all HTIFEs.

Example 4.2. Let $X=\left\{x_{1}, x_{2}\right\}$ be a fixed set, and $h_{E}^{\prime}\left(x_{1}\right)=\{((5,8,9) ; 0.6,0.3),((6,7,8) ; 0.5,0.3),((4,7,8) ; 0.6$, $0.3)\}$ and $h_{E}^{\prime}\left(x_{2}\right)=\{((4,6,10) ; 0.4,0.3),((5,7,9) ; 0.7,0.2)\}$ be the HTIFEs of $x_{\mathfrak{i}}(i=1,2)$ to a set $E$. E can be considered an HTIFS, and can be denoted as follows:

$$
\begin{aligned}
E=\{ & <x_{1},\{((5,8,9) ; 0.6,0.3),((6,7,8) ; 0.5,0.3),((4,7,8) ; 0.6,0.3)\}>, \\
& \left.<x_{2},\{((4,6,10) ; 0.4,0.3),((5,7,9) ; 0.7,0.2)\}>\right\} .
\end{aligned}
$$

\subsection{Some aggregating operators with hesitant triangular intuitionistic fuzzy information}

Definition 4.3. Let $\tilde{a}^{\prime}=\bigcup_{i}\left(\left(\underline{a}_{i}, a_{i}, \bar{a}_{i}\right) ; \omega_{i}, u_{i}\right)$ and $\tilde{b}^{\prime}=\bigcup_{i}\left(\left(\underline{b}_{j}, b_{j}, \bar{b}_{j}\right) ; \omega_{j}, u_{j}\right)$ be two HTIFEs and $\lambda>0$, the operations are given as follows:

(1) $\lambda \tilde{a}^{\prime}=\bigcup_{i}\left\{\left(\left(\lambda \underline{a}_{i}, \lambda a_{i}, \lambda \bar{a}_{i}\right) ; \omega_{i}, u_{i}\right)\right\}$,

(2) $\tilde{a}^{\prime \lambda}=\bigcup_{i}\left\{\left(\left(\underline{a}_{i}^{\lambda}, a_{i}^{\lambda}, \bar{a}_{i}^{\lambda}\right) ; \omega_{j}, u_{j}\right)\right\}$, 
(3) $\tilde{a}^{\prime}+\tilde{b}^{\prime}=\bigcup_{i, j}\left\{\left(\left(\underline{a}_{i}+\underline{a}_{j}, a_{i}+b_{j}, \bar{a}_{i}+\bar{b}_{j}\right) ; \min \left\{\omega_{i}, \omega_{j}\right\}, \max \left\{u_{i}, u_{j}\right\}\right)\right\}$,

(4) $\tilde{a}^{\prime} \tilde{b}^{\prime}= \begin{cases}\bigcup_{i, j}\left\{\left(\left(\underline{a}_{i} \underline{b}_{j}, a b, \bar{a} \bar{b}\right) ; \min \left\{\omega_{\tilde{a}_{i}}, \omega_{\tilde{b}_{j}}\right\}, \max \left\{u_{\tilde{a}_{i}}, u_{\tilde{b}_{j}}\right\}\right)\right\}, & \text { if } \tilde{a}_{i}>0 \text { and } \tilde{b}_{j}>0, \\ \bigcup_{i, j}\left\{\left(\left(\underline{a}_{i} \bar{b}_{j}, a_{i} b_{j}, \bar{a}_{i} \underline{b}_{j}\right) ; \min \left\{\omega_{\tilde{a}_{i}}, \omega_{\tilde{b}_{j}}\right\}, \max \left\{u_{\tilde{a}_{i}}, u_{\tilde{b}_{j}}\right\}\right)\right\}, & \text { if } \tilde{a}_{i}<0 \text { and } \tilde{b}_{j}>0, \\ \bigcup_{i, j}\left\{\left(\left(\bar{a}_{i} \bar{b}_{j}, a_{i} b_{j}, \underline{a}_{i} \underline{b}_{j}\right) ; \min \left\{\omega_{\tilde{a}_{i}}, \omega_{\tilde{b}_{j}}\right\}, \max \left\{u_{\tilde{a}_{i}}, u_{\tilde{b}_{j}}\right\}\right)\right\}, & \text { if } \tilde{a}_{i}<0 \text { and } \tilde{b}_{j}<0 .\end{cases}$

For comparing two HTIFEs, we give the score function as follows:

Definition 4.4. Let $\tilde{h}^{\prime}=\bigcup_{i}\left(\left(\underline{a}_{i}, a_{i}, \bar{a}_{i}\right) ; w_{i}, u_{i}\right)(i=1,2, \ldots, 1(h))$ be an HTIFE and

$$
s(h)=\frac{1}{l\left(h^{\prime}\right)} \sum_{i=1}^{l\left(h^{\prime}\right)} \frac{\left(\underline{a}_{i}+2 a_{i}+\bar{a}_{i}\right)\left(\omega_{i}-u_{i}\right)}{4 a^{*}}
$$

be the score function of $h^{\prime}$, where $l\left(h^{\prime}\right)$ is the number of the triangular intuitionistic fuzzy values in $\tilde{h}^{\prime}$, and $a^{*}$ is the standardized constant. For two HTIFEs $h_{1}^{\prime}$ and $h_{2}^{\prime}$, if $s\left(h_{1}^{\prime}\right)>s\left(h_{2}^{\prime}\right)$, then $h_{1}^{\prime} \succ h_{2}^{\prime}$, and, if $s\left(h_{1}^{\prime}\right)=s\left(h_{2}^{\prime}\right)$, then $h_{1}^{\prime}=h_{2}^{\prime}$.

Based on the operational principle for HTIFEs, we develop the hesitant triangular intuitionistic fuzzy weighted averaging (HTIFWA) operator and hesitant triangular intuitionistic fuzzy ordered weighted averaging (HTIFOWA) operator.

Definition 4.5. Let $\tilde{h}_{j}^{\prime}=\bigcup_{i}\left(\left(\underline{a}_{i j}, a_{i j}, \bar{a}_{i j}\right) ; \omega_{i j}, u_{i j}\right)(j=1,2, \ldots, n)$ be a collection of HTIFEs. Let HTIFWA: $\Omega^{\mathrm{n}} \rightarrow \Omega$, if

$$
\operatorname{HTIFWA}\left(\tilde{h}_{1}^{\prime}, \tilde{h}_{2}^{\prime}, \ldots, \tilde{h}_{n}^{\prime}\right)=\sum_{j=1}^{n} w_{j} \tilde{h}_{j}^{\prime}=\bigcup_{i}\left\{\left(\left(\sum_{j=1}^{n} w_{j} \underline{a}_{i j}, \sum_{j=1}^{n} w_{j} a_{i j}, \sum_{j=1}^{n} w_{i j} \bar{a}_{j}\right) ; \min _{j} w_{i j}, \max _{j} u_{i j}\right)\right\},
$$

where $\Omega$ is the set of all HTIFEs, $w_{j}$ is the weight of $\tilde{h}_{j}^{\prime}$ satisfying that $w_{j} \in[0,1](j=1,2, \ldots, n)$ and $\sum_{j=1}^{n} w_{j}=1$.

Definition 4.6. Let $\tilde{h}_{j}^{\prime}=\bigcup_{i}\left(\left(\underline{a}_{i j}, a_{i j}, \bar{a}_{i j}\right) ; \omega_{i j}, u_{i j}\right)(j=1,2, \ldots, n)$ be a collection of HTIFEs. Let HTIFWA: $\Omega^{\mathrm{n}} \rightarrow \Omega$, if

$$
\begin{aligned}
\operatorname{HTIFOWA}\left(\tilde{h}_{1}^{\prime}, \tilde{h}_{2}^{\prime}, \ldots, \tilde{h}_{n}^{\prime}\right) & =\sum_{j=1}^{n} w_{j} \tilde{h}_{\sigma(j)}^{\prime} \\
& =\bigcup_{(i)}\left\{\left(\left(\sum_{j=1}^{n} w_{j} \underline{a}_{\sigma(i j)}, \sum_{j=1}^{n} w_{j} a_{\sigma(i j)}, \sum_{j=1}^{n} w_{j} \bar{a}_{\sigma(i j)}\right) ; \min _{j} \omega_{\sigma(i j)}, \max _{j} u_{\sigma(i j)}\right)\right\},
\end{aligned}
$$

where $\Omega$ is the set of all HTIFEs, $w_{j}$ is the weight of $\tilde{h}_{j}^{\prime}$ satisfying that $w_{j} \in[0,1](j=1,2, \ldots, n)$ and $\sum_{j=1}^{n} w_{j}=1,(\sigma(i 1), \sigma(i 2), \ldots, \sigma(i n))$ is a permutation of $(1,2, \ldots, n)$, such that $\tilde{h}_{(j)}^{\prime} \leqslant \tilde{h}_{(j+1)}^{\prime}$ for all $j=$ $1,2, \ldots, n-1$.

In the following, we propose the hesitant triangular intuitionistic fuzzy weighted geometric (HTIFWG) operator and hesitant triangular intuitionistic fuzzy ordered weighted geometric (HTIFOWG) operator.

Definition 4.7. Let $\tilde{h}_{j}^{\prime}=\bigcup_{i}\left(\left(\underline{a}_{i j}, a_{i j}, \bar{a}_{i j}\right) ; \omega_{i j}, u_{i j}\right)(j=1,2, \ldots, n)$ be a collection of HTIFEs with $\underline{a}_{j}>0$. Let HTIFWG: $\Omega^{n} \rightarrow \Omega$, if

$$
\operatorname{HTIFWG}\left(\tilde{h}_{1}^{\prime}, \tilde{h}_{2}^{\prime}, \ldots, \tilde{h}_{n}^{\prime}\right)=\prod_{j=1}^{n} \tilde{h}_{j}^{\prime w_{j}}=\bigcup_{i}\left\{\left(\left(\prod_{j=1}^{n} \underline{a}_{i j}^{w_{j}}, \prod_{j=1}^{n} a_{i j}^{w_{j}}, \prod_{j=1}^{n} \bar{a}_{i j}^{w_{j}}\right) ; \min _{j} \omega_{i j}, \max _{j} u_{i j}\right)\right\},
$$

where $\Omega$ is the set of all HTIFEs, $w_{j}$ is the weight of $\tilde{h}_{j}^{\prime}$ satisfying that $w_{j} \in[0,1](j=1,2, \ldots, n)$ and $\sum_{j=1}^{n} w_{j}=1$. 
Definition 4.8. Let $\tilde{h}_{j}^{\prime}=\bigcup_{i}\left(\left(\underline{a}_{i j}, a_{i j}, \bar{a}_{i j}\right) ; \omega_{i j}, u_{i j}\right)(j=1,2, \ldots, n)$ be a collection of HTIFEs with $\underline{a}_{j}>0$. Let HTIFWG: $\Omega^{\mathrm{n}} \rightarrow \Omega$, if

$$
\begin{aligned}
\operatorname{HTIFOWG}\left(\tilde{\mathrm{h}}_{1}^{\prime}, \tilde{\mathrm{h}}_{2}^{\prime}, \ldots, \tilde{\mathrm{h}}_{\mathfrak{n}}^{\prime}\right) & =\prod_{j=1}^{n}\left(\tilde{\mathrm{h}}_{\sigma(j)}^{\prime}\right)^{w_{j}} \\
& =\bigcup_{i}\left\{\left(\left(\prod_{j=1}^{n}\left(\underline{a}_{\sigma(i j)}\right)^{w_{j}}, \prod_{j=1}^{n}\left(a_{\sigma(i j)}\right)^{w_{j}}, \prod_{j=1}^{n}\left(\bar{a}_{\sigma(i j)}\right)^{w_{j}}\right) ; \min _{j} \omega_{i j}, \max _{j} u_{i j}\right)\right\},
\end{aligned}
$$

where $\Omega$ is the set of all HTIFEs, $w_{j}$ is the weight of $\tilde{h}_{j}^{\prime}$ satisfying that $w_{j} \in[0,1](j=1,2, \ldots, n)$ and $\sum_{j=1}^{n} w_{j}=1$, and $(\sigma(i 1), \sigma(i 2), \ldots, \sigma(i n))$ is a permutation of $(1,2, \ldots, n)$, such that $\tilde{h}_{(j)}^{\prime} \leqslant \tilde{h}_{(j+1)}^{\prime}$ for all $j=1,2, \ldots, n-1$.

We can aggregate hesitant triangular intuitionistic fuzzy information by Definitions 4.5, 4.6, 4.7, 4.8.

\subsection{Some aggregating operators with the standardized hesitant triangular intuitionistic fuzzy information}

Based on TIFNs and the (3.1) and (3.2), we give the following definition.

Definition 4.9. Let $\tilde{h}^{\prime}=\bigcup_{i}\left(\left(\underline{a}_{i}, a_{i}, \bar{a}_{i}\right) ; \omega_{i}, u_{i}\right)(i=1,2, \ldots, l(h))$ be an HTIFE and $\mu_{\left(\tilde{a}_{i}\right)}^{*}=\frac{\left(a_{i}+4 a_{i}+\bar{a}_{i}\right) \omega_{i}}{6 a^{*}\left(1+\omega_{i}-u_{i}\right)}$, $v_{\left(\tilde{a}_{i}\right)}^{*}=\frac{\left(a_{i}+4 a_{i}+\bar{a}_{i}\right)\left(1-\mu_{i}\right)}{6 a^{*}\left(1+\omega_{i}-u_{i}\right)}$ be the values of the membership degree and the non-membership degree of the HTIFE. Then we call $\tilde{\mathrm{H}}_{\mathrm{E}(\mathrm{x})}^{\prime}=\bigcup_{i}\left\{\left(\mu_{\left(\tilde{\mathrm{a}}_{i}\right)}^{*}, v_{\left(\tilde{\mathrm{a}}_{i}\right)}^{*}\right)\right\}\left(i=1,2, \ldots, l\left(\tilde{\mathrm{H}}^{\prime}\right)\right)$ the standardized HTIFE $\left(l\left(\tilde{\mathrm{H}}^{\prime}\right)\right.$ is the length of the standardized HTIFE), and $E=\left\{<x, \tilde{H}_{E(x)}^{\prime}>\mid x \in X\right\}$ the standardized HTIFS. For convenience, we call it S-HTIFS for short.

Example 4.10. As it is showen like Example 4.2, we get $E=\left\{<x_{1},\{((5,8,9) ; 0.6,0.3),((6,7,8) ; 0.5,0.3)\right.$, $\left.((4,7,8) ; 0.6,0.3)\}>,<x_{2},\{((4,6,10) ; 0.4,0.3),((5,7,9) ; 0.7,0.2)\}>\right\}$. And $a *=10$, then $\mu_{\left(\tilde{a}_{i}\right)}^{*}=\frac{\left(a_{i}+4 a_{i}+\bar{a}_{i}\right) \omega_{i}}{6 a^{*}\left(1+\omega_{i}-\mathfrak{u}_{i}\right)}$, $v_{\left(\tilde{a}_{i}\right)}^{*}=\frac{\left(\underline{a}_{i}+4 a_{i}+\bar{a}_{i}\right)\left(1-\mu_{i}\right)}{6 a^{*}\left(1+\omega_{i}-u_{i}\right)}$. So we can easily calculate that

$$
E=\left\{<x_{1},\{(0.35,0.41),(0.29,0.41),(0.31,0.36)\}>,<x_{2},\{(0.23,0.40),(0.33,0.37)\}>\right\} .
$$

Given two standardized HTIFEs $\left.\tilde{A}^{\prime}=\bigcup_{i}\left\{\left(\mu_{(} \tilde{a}_{i}\right)^{*}, v_{(} \tilde{a}_{i}\right)^{*}\right\}$ and $\left.\tilde{B}^{\prime}=\bigcup_{j}\left\{\left(\mu_{(} \tilde{b}_{j}\right)^{*}, v_{(} \tilde{b}_{j}\right)^{*}\right\}$ and $\lambda>0$, inspired by the operations of hesitant fuzzy set [12], we give the following operations:

(1) $\lambda \tilde{A}^{\prime}=\bigcup_{i}\left\{\left(1-\left(1-\mu_{\left(\tilde{a}_{i}\right)}^{*}\right)^{\lambda},\left(1-\left(1-v_{\left(\tilde{a}_{i}\right)}^{*}\right)^{\lambda}\right\}\right.\right.$;

(2) $\tilde{A}^{\prime \lambda}=\bigcup_{i}\left\{\mu_{\left(\tilde{a}_{i}\right)}^{*}, \nu_{\left(\tilde{a}_{i}\right)}^{*}{ }^{\lambda}\right\}$;

(3) $\tilde{A}^{\prime} \oplus \tilde{B}^{\prime}=\bigcup_{i, j}\left\{\left(\mu_{\left(\tilde{a}_{i}\right)}^{*}+\mu_{\left(\tilde{b}_{j}\right)}^{*}-\mu_{\left(\tilde{a}_{i}\right)}^{*} \mu_{\left(\tilde{b}_{j}\right)}^{*} v_{\left(\tilde{a}_{i}\right)}^{*}+v_{\left(\tilde{b}_{j}\right)}^{*}-v_{\left(\tilde{a}_{i}\right)}^{*} v_{\left(\tilde{b}_{j}\right)}^{*}\right)\right\}$;

(4) $\tilde{A}^{\prime} \otimes \tilde{B}^{\prime}=\bigcup_{i, j}\left\{\left(\mu_{\left(\tilde{a}_{i}\right)}^{*} \mu_{\left(\tilde{b}_{j}\right)}^{*}, v_{\left(\tilde{a}_{i}\right)}^{*} v_{\left(\tilde{b}_{j}\right)}^{*}\right)\right\}$.

Definition 4.11. For a standardized HTIFE $\tilde{H}^{\prime}=\bigcup_{i}\left\{\left(\mu_{\left(\tilde{a}_{i}\right)}^{*}, v_{\left(\tilde{a}_{i}\right)}^{*}\right)\right\}(i=1,2, \ldots, l(H)), s\left(\tilde{H}^{\prime}\right)=\frac{1}{l\left(H^{\prime}\right)} \sum_{i=1}^{l\left(H^{\prime}\right)}$ $\left(\mu_{\left(\tilde{a}_{i}\right)}^{*}-v_{\left(\tilde{a}_{i}\right)}^{*}\right)$ is called the score function of $\tilde{H}^{\prime}$. For two standardized HTIFEs $H_{1}^{\prime}$ and $H_{2}^{\prime}$, if $s\left(H_{1}^{\prime}\right)>s\left(H_{2}^{\prime}\right)$, then $\mathrm{H}_{1}^{\prime} \succ \mathrm{H}_{2}^{\prime}$, and, if $\mathrm{s}\left(\mathrm{H}_{1}^{\prime}\right)=\mathrm{s}\left(\mathrm{H}_{2}^{\prime}\right)$, then $\mathrm{H}_{1}^{\prime}=\mathrm{H}_{2}^{\prime}$.

Based on the above operations for the standardized HTIFEs, we also introduce the standardized hesitant triangular fuzzy weighted averaging (S-HTIFWA) operator, the standardized hesitant triangular fuzzy ordered weighted averaging (S-HTIFOWA) operator, the standardized hesitant triangular fuzzy weighted geometric (S-HTIFWG) operator and the standardized hesitant triangular fuzzy ordered weighted geometric (S-HTIFOWG) operator.

Definition 4.12. Let $\tilde{H}_{j}^{\prime}=\bigcup_{i}\left\{\left(\mu_{\left(\tilde{a}_{i j}\right)}^{*}, v_{\left(\tilde{a}_{i j}\right)}^{*}\right)\right\}$ be the standardized HTIFE. The standardized hesitant triangular fuzzy weighted averaging operator is a mapping $\Omega^{n} \rightarrow \Omega$ such that

$$
\operatorname{S-HTIFWA}\left(\tilde{\mathrm{H}}_{1}^{\prime}, \tilde{\mathrm{H}}_{2}^{\prime}, \ldots, \tilde{\mathrm{H}}_{n}^{\prime}\right)=\oplus_{j=1}^{n} w_{j} \tilde{\mathrm{H}}_{j}^{\prime}=\bigcup_{i}\left\{\left(1-\prod_{j=1}^{n}\left(1-\mu_{\left(\tilde{\mathrm{a}}_{i j}\right)}^{*}\right)^{w_{j}}, 1-\prod_{j=1}^{n}\left(1-v_{\left(\tilde{a}_{i j}\right)}^{*}\right)^{w_{j}}\right)\right\},
$$

where $\Omega$ is the set of all HTIFEs, $w_{j}$ is the weight vector of $\tilde{H}_{j}^{\prime}$, and $w_{j} \in[0,1](j=1,2, \ldots, n), \sum_{j=1}^{n} w_{j}=1$. 
Definition 4.13. Let $\tilde{\mathrm{H}}_{j}^{\prime}=\bigcup_{i}\left\{\left(\mu_{\left(\tilde{a}_{i j}\right)}^{*}, v_{\left(\tilde{a}_{i j}\right)}^{*}\right)\right\}$ be the standardized HTIFE. The standardized hesitant triangular fuzzy ordered weighted averaging operator of dimension $n$ is a mapping $\Omega^{n} \rightarrow \Omega$, that has an associated weight vector $w=\left(w_{1}, w_{2}, \ldots w_{n}\right)^{\top}$ such that $w_{j}>0$ and $\sum_{j=1}^{n} w_{j}=1$. Furthermore,

$$
\operatorname{S-HTIFOWA}\left(\tilde{\mathrm{H}}_{1}^{\prime}, \tilde{\mathrm{H}}_{2}^{\prime}, \ldots, \tilde{\mathrm{H}}_{n}^{\prime}\right)=\oplus_{j=1}^{n} w_{j} \tilde{\mathrm{H}}_{\sigma(j)}^{\prime}=\bigcup_{i}\left\{\left(1-\prod_{j=1}^{n}\left(1-\mu_{\left(\tilde{\mathrm{a}}_{\sigma(i)}\right)}^{*}\right)^{w_{j}}, 1-\prod_{j=1}^{n}\left(1-v_{\left(\tilde{\mathrm{a}}_{\sigma(i)}\right)}^{*}\right)^{w_{j}}\right)\right\},
$$

where $(\sigma(\mathfrak{i} 1), \sigma(\mathfrak{i} 2), \ldots, \sigma(\mathfrak{i n}))$ is a permutation of $(1,2, \ldots, n)$, such that $\tilde{H}_{(j)}^{\prime} \leqslant \tilde{H}_{(j+1)}^{\prime}$ for all $j=1,2, \ldots, n-1$.

Definition 4.14. Let $\tilde{H}_{j}^{\prime}=\bigcup_{i}\left\{\left(\mu_{\left(\tilde{a}_{i j}\right)}^{*}, v_{\left(\tilde{a}_{i j}\right)}^{*}\right)\right\}$ be the standardized HTIFE. The standardized hesitant triangular fuzzy weighted geometric operator is a mapping $\Omega^{n} \rightarrow \Omega$ such that

$$
\text { S-HTIFWG }\left(\tilde{\mathrm{H}}_{1}^{\prime}, \tilde{\mathrm{H}}_{2}^{\prime}, \ldots, \tilde{\mathrm{H}}_{n}^{\prime}\right)=\otimes_{j=1}^{n} w_{j} \tilde{\mathrm{H}}_{j}^{\prime}=\bigcup_{i}\left\{\left(\prod_{j=1}^{n}\left(\mu_{\left(\tilde{\mathrm{a}}_{i j}\right)}^{*}\right)^{w_{j}}, \prod_{j=1}^{n}\left(v_{\left(\tilde{a}_{\mathfrak{i}}\right)}^{*}\right)^{w_{j}}\right)\right\},
$$

where $\Omega$ is the set of all HTIFEs, $w_{j}$ is the weight vector of $\tilde{H}_{j}^{\prime}$, and $w_{j} \in[0,1](j=1,2, \ldots, n), \sum_{j=1}^{n} w_{j}=1$.

Definition 4.15. Let $\tilde{\mathrm{H}}_{j}^{\prime}=\bigcup_{i}\left\{\left(\mu_{\left(\tilde{a}_{i j}\right)}^{*}, v_{\left(\tilde{a}_{i j}\right)}^{*}\right)\right\}$ be the standardized HTIFE. The standardized hesitant triangular fuzzy ordered weighted geometric operator of dimension $n$ is a mapping $\Omega^{n} \rightarrow \Omega$, that has an associated weight vector $w=\left(w_{1}, w_{2}, \ldots w_{n}\right)^{\top}$ such that $w_{j}>0$ and $\sum_{j=1}^{n} w_{j}=1$. Furthermore,

$$
\operatorname{S-HTIFOWG}\left(\tilde{\mathrm{H}}_{1}^{\prime}, \tilde{\mathrm{H}}_{2}^{\prime}, \ldots, \tilde{\mathrm{H}}_{n}^{\prime}\right)=\otimes_{j=1}^{n} w_{j} \tilde{\mathrm{H}}_{\sigma(j)}^{\prime}=\bigcup_{i}\left\{\left(\prod_{j=1}^{n}\left(\mu_{\left(\tilde{a}_{\sigma(i)}\right)}^{*}\right)^{w_{j}}, \prod_{j=1}^{n}\left(v_{\left(\tilde{a}_{\sigma(i j)}\right)}^{*}\right)^{w_{j}}\right)\right\},
$$

where $(\sigma(\mathfrak{i} 1), \sigma(\mathfrak{i} 2), \ldots, \sigma(\mathfrak{i n}))$ is a permutation of $(1,2, \ldots, n)$, such that $\tilde{H}_{(\mathfrak{j})}^{\prime} \leqslant \tilde{H}_{(j+1)}^{\prime}$ for all $j=1,2, \ldots, n-1$.

\subsection{The distance measure of hesitant triangular intuitionistic fuzzy sets}

In order to improve the distance measure of hesitant fuzzy sets, Li et al. [8] gave the hesitance degree of hesitant fuzzy set. Similarly, we give the hesitance degree of hesitant triangular intuitionistic fuzzy set.

Definition 4.16. Let $h^{\prime}$ be a hesitant triangular intuitionistic fuzzy set on $X=\left\{x_{1}, x_{2}, \ldots x_{n}\right\}$, and for any $x_{i} \in X, l\left(h^{\prime}\left(x_{i}\right)\right)$ be the length of $h^{\prime}\left(x_{i}\right)$. Denote

$$
\begin{aligned}
u\left(h^{\prime}\left(x_{i}\right)\right) & =1-\frac{1}{l\left(h^{\prime}\left(x_{i}\right)\right)}, \\
u\left(h^{\prime}\right) & =\frac{1}{n} \sum_{i=1}^{n} u\left(h^{\prime}\left(x_{i}\right)\right),
\end{aligned}
$$

where $u\left(h^{\prime}\left(x_{i}\right)\right)$ is the hesitance degree of $h^{\prime}\left(x_{i}\right)$, and $u\left(h^{\prime}\right)$ the hesitance degree of $h^{\prime}$, respectively.

For the number of elements of a HTIFE, we denote $l\left(h_{E(x)}^{\prime}\right)$ as the number of elements. When $l\left(h_{\mathrm{P}(x)}^{\prime}\right) \neq l\left(h_{\mathrm{Q}(x)}^{\prime}\right)$ with two HTIFEs $h_{\mathrm{P}(\mathrm{x})}^{\prime}$ and $h_{\mathrm{Q}(\mathrm{x})}^{\prime}$, we add the shorter one with some values. The problem is how to select the value. We give a method as follows:

For a HTIFE $h_{E}^{\prime}(x)=\left\{\tilde{a}_{1}, \tilde{a}_{2}, \ldots, \tilde{a}_{n}\right\}\left(\tilde{a}_{i}=\left(\left(\underline{a}_{i}, a_{i}, \bar{a}_{i}\right) ; \omega_{i}, u_{i}\right)\right), \tilde{a}_{n+i}=\alpha_{1} \tilde{a}_{1}+\alpha_{2} \tilde{a}_{2}+\ldots+\alpha_{n} \tilde{a}_{n}$ is the added one for the shorter HTIFE, where $\alpha_{1}, \alpha_{2}, \ldots, \alpha_{n}$ are the weight of $\tilde{a}_{1}, \tilde{a}_{2}, \ldots, \tilde{a}_{n}$, respectively, $i=1,2, \ldots, \alpha_{1}+\alpha_{2}+\ldots+\alpha_{n}=1$. When $\alpha_{1}=\alpha_{2}=\ldots=\alpha_{n}=\frac{1}{n}, \tilde{a}_{n+i}=\frac{\tilde{a}_{1}+\tilde{a}_{2}+\ldots+\tilde{a}_{n}}{n}$. Obviously, the added value of a HTIFS depends on the existing HTIFEs. In $[8,19]$, the added one of a HFS depends on the decision makers' risk preferences and the decision makers always hold a pessimistic attitude subjectively, the method is more objective than that of $[8,19]$. On the other hand, as the information of HTIFEs is given by decision makers, the weights can reflect the importance of different decision makers in decision making problem.

Based on Definitions 3.3, 4.1, and 4.16, we give some distances of HTIFSs in the following. 
Definition 4.17. Let $h_{k}^{\prime}, h_{t}^{\prime}$ be two HTIFSs on $X=\left\{x_{1}, x_{2}, \ldots x_{n}\right\}$ and

$$
h_{k}^{\prime}\left(x_{j}\right)=\bigcup_{i}\left(\left(\underline{a}_{i j}, a_{i j}, \bar{a}_{i j}\right) ; \omega_{\tilde{a}_{i j}}, \mu_{\tilde{a}_{i j}}\right), \quad h_{t}^{\prime}\left(x_{j}\right)=\bigcup_{i}\left(\left(\underline{b}_{i j}, a_{i j}, \bar{b}_{i j}\right) ; \omega_{\tilde{b}_{i j}}, \mu_{\tilde{b}_{i j}}\right)
$$

be two HTIFEs, where $k, t=1,2, \ldots, m$, then the distance is defined as

$$
\begin{aligned}
d_{h t h}\left(h_{k}^{\prime}, h_{t}^{\prime}\right)= & \frac{1}{2 n} \sum_{j=1}^{n}\left[\left|u\left(h_{k}^{\prime}\left(x_{j}\right)\right)-u\left(h_{t}^{\prime}\left(x_{j}\right)\right)\right|+\frac{1}{2 l_{x_{j}}} \sum_{i=1}^{l_{x_{j}}}\left(\lambda \left(\left|V_{\mu}\left(\tilde{a}_{i j}^{\sigma(k)}\right)^{*}-V_{\mu}\left(\tilde{b}_{i j}^{\sigma(k)}\right)^{*}\right|+\mid V_{v}\left(\tilde{a}_{i j}^{\sigma(k)}\right)^{*}\right.\right.\right. \\
& \left.\left.\left.-V_{v}\left(\tilde{b}_{i j}^{\sigma(k)}\right)^{*} \mid\right)+(1-\lambda)\left(\left|A_{\mu}\left(\tilde{a}_{i j}^{\sigma(k)}\right)^{*}-A_{\mu}\left(\tilde{b}_{i j}^{\sigma(k)}\right)^{*}\right|+\left|A_{v}\left(\tilde{a}_{i j}^{\sigma(k)}\right)^{*}-A_{v}\left(\tilde{b}_{i j}^{\sigma(k)}\right)^{*}\right|\right)\right)\right],
\end{aligned}
$$

where

$$
\begin{array}{ll}
V_{\mu}\left(\tilde{a}_{i j}^{\sigma(k)}\right)^{*}=\frac{\left(\underline{a}_{i j}^{\sigma(k)}+4 a_{i j}^{\sigma(k)}+\bar{a}_{i j}^{\sigma(k)}\right) \omega_{\tilde{a}_{i j}^{\sigma(k)}}}{6 a^{*}}, \quad V_{\mu}\left(\tilde{b}_{i j}^{\sigma(k)}\right)^{*}=\frac{\left(\underline{b}_{i j}^{\sigma(k)}+4 b_{i j}^{\sigma(k)}+\bar{b}_{i j}^{\sigma(k)}\right) \omega_{\tilde{b}_{i j}^{\sigma(k)}}}{6 b^{*}}, \\
v_{v}\left(\tilde{a}_{i j}^{\sigma(k)}\right)^{*}=\frac{\left(\underline{a}_{i j}^{\sigma(k)}+4 a_{i j}^{\sigma(k)}+\bar{a}_{i j}^{\sigma(k)}\right)\left(1-\mu_{\tilde{a}_{i j}^{\sigma(k)}}\right)}{6 a^{*}}, & v_{v}\left(\tilde{b}_{i j}^{\sigma(k)}\right)^{*}=\frac{\left(\underline{b}_{i j}^{\sigma(k)}+4 b_{i j}^{\sigma(k)}+\bar{b}_{i j}^{\sigma(k)}\right)\left(1-\mu_{\tilde{b}_{i j}^{\sigma(k)}}\right)}{6 b^{*}}, \\
A_{\mu}\left(\tilde{a}_{i j}^{\sigma(k)}\right)^{*}=\frac{\left(\bar{a}_{i j}^{\sigma(k)}-\underline{a}_{i j}^{\sigma(k)}\right) \omega_{\tilde{a}_{i j}^{\sigma(k)}}}{3 a^{*}}, & A_{\mu}\left(\tilde{b}_{i j}^{\sigma(k)}\right)^{*}=\frac{\left(\bar{b}_{i j}^{\sigma(k)}-\underline{b}_{i j}^{\sigma(k)}\right) \omega_{\tilde{b}_{i j}^{\sigma(k)}}}{3 b^{*}}, \\
A_{v}\left(\tilde{a}_{i j}^{\sigma(k)}\right)^{*}=\frac{\left(\bar{a}_{i j}^{\sigma(k)}-\underline{a}_{i j}^{\sigma(k)}\right)\left(1-\mu_{\tilde{a}_{i j}^{\sigma(k)}}\right)}{3 a^{*}}, & A_{v}\left(\tilde{b}_{i j}^{\sigma(k)}\right)^{*}=\frac{\left(\bar{b}_{i j}^{\sigma(k)}-\underline{b}_{i j}^{\sigma(k)}\right)\left(1-\mu_{\tilde{b}_{i j}^{\sigma(k)}}\right)}{3 b^{*}},
\end{array}
$$

$l_{x_{i}}=\max _{q \in I}\left\{l\left(h_{q}^{\prime}\left(x_{i}\right)\right)\right\}, I=\{1,2, \ldots, m\}, 0 \leqslant \lambda \leqslant 1$, and $h_{k}\left(x_{j}\right)^{\sigma(k)}=\bigcup_{i}\left(\left(\underline{a}_{i j}^{\sigma(k)}, a_{i j}^{\sigma(k)}, \bar{a}_{i j}^{\sigma(k)}\right) ; \omega_{\tilde{a}_{i j}}, \mu_{\tilde{a}_{i j}}\right)$ and $h_{t}\left(x_{j}\right)^{\sigma(k)}=\bigcup_{i}\left(\left(\underline{b}_{i j}^{\sigma(k)}, a_{i j}^{\sigma(k)}, \bar{b}_{i j}^{\sigma(k)}\right) ; \omega_{\tilde{b}_{i j}^{\sigma(k)}}, \mu_{\tilde{b}_{i j}^{\sigma(k)}}\right)$ are the jth values in $h_{k}\left(x_{j}\right)$ and $h_{t}\left(x_{j}\right)$, respectively, $a^{*}$ and $b^{*}$ are standardized constants.

We give an example to illustrate the calculating process of $d_{h t h}$ :

Example 4.18. Assume that

$$
\begin{aligned}
& h_{1}=\left\{<x_{1},\{((3,4,5) ; 0.4,0.3),((5,6,7) ; 0.5,0.3)\},<x_{2},\{((3,5,7) ; 0.6,0.2)\}\right\}, \\
& h_{2}^{\prime}=\left\{<x_{1},\{((3,4,6) ; 0.6,0.3),((5,7,7) ; 0.4,0.3),((4,7,10) ; 0.7,0.1)\},<x_{2},\{((3,4,6) ; 0.5,0.1)\}\right\} .
\end{aligned}
$$

So $\mathrm{a}^{*}=\max \left\{\overline{\mathrm{a}}_{\mathfrak{i}}, \overline{\mathrm{b}}_{\mathfrak{i}}\right\}=10$. And we consider $\tilde{\mathrm{a}}_{\mathrm{n}+\mathrm{i}}=\frac{\tilde{\mathrm{a}}_{1}+\tilde{\mathrm{a}}_{2}}{2}$ to extend the shorter HTIFE, we can obtain

$$
h_{1}^{\prime}=\left\{<x_{1},\{((3,4,5) ; 0.4,0.3),((5,6,7) ; 0.5,0.3)((4,5,6) ; 0.4,0.3)\},<x_{2},\{((3,5,7) ; 0.6,0.2)\}\right\} .
$$

Let $\lambda=0.5$, then $d_{\text {hth }}=\frac{1}{4}\left[1 \frac{1}{2}-\frac{2}{3} \mid+\frac{1}{6} \times\left((0.5 \times 0.4+0.5 \times 0.12)+\left(0.5 \times \frac{6.5}{60}+0.5 \times \frac{1.7}{30}\right)+\left(0.5 \times \frac{22}{60}+0.5 \times\right.\right.\right.$ $\left.0))+|0-0|+\frac{1}{2} \times\left(0.5 \times \frac{7}{60}+0.5 \times \frac{7}{150}\right)\right]=0.074$.

Considering the preferences between the hesitance degree and the values and ambiguities of TIFNs, we propose the distance with preferences as follows:

Definition 4.19. Let $h_{k}^{\prime}, h_{t}^{\prime}$ be two HTIFSs on $X=\left\{x_{1}, x_{2}, \ldots x_{n}\right\}$ and $h_{k}^{\prime}\left(x_{j}\right)=\bigcup_{i}\left(\left(\underline{a}_{i j}, a_{i j}, \bar{a}_{i j}\right) ; \omega_{\tilde{a}_{i j}}, \mu_{\tilde{a}_{i j}}\right)$, $h_{t}^{\prime}\left(x_{j}\right)=\bigcup_{i}\left(\left(\underline{b}_{i j}, a_{i j}, \bar{b}_{i j}\right) ; \omega_{\tilde{b}_{i j}}, \mu_{\tilde{b}_{i j}}\right)$ be two HTIFEs, $k, t=1,2, \ldots, m$, then the distance measure is defined as

$$
\begin{aligned}
d_{p h t h}\left(h_{k}^{\prime}, h_{t}^{\prime}\right)= & \frac{1}{n} \sum_{j=1}^{n}\left[\alpha\left|u\left(h_{k}^{\prime}\left(x_{j}\right)\right)-u\left(h_{t}^{\prime}\left(x_{j}\right)\right)\right|+\frac{1-\alpha}{2 l_{x_{j}}} \sum_{i=1}^{l_{x_{j}}}\left(\lambda \left(\left|V_{\mu}\left(\tilde{a}_{i j}^{\sigma(k)}\right)^{*}-V_{\mu}\left(\tilde{b}_{i j}^{\sigma(k)}\right)^{*}\right|+\mid V_{v}\left(\tilde{a}_{i j}^{\sigma(k)}\right)^{*}\right.\right.\right. \\
& \left.\left.\left.-V_{v}\left(\tilde{b}_{i j}^{\sigma(k)}\right)^{*} \mid\right)+(1-\lambda)\left(\left|A_{\mu}\left(\tilde{a}_{i j}^{\sigma(k)}\right)^{*}-A_{\mu}\left(\tilde{b}_{i j}^{\sigma(k)}\right)^{*}\right|+\left|A_{v}\left(\tilde{a}_{i j}^{\sigma(k)}\right)^{*}-A_{v}\left(\tilde{b}_{i j}^{\sigma(k)}\right)^{*}\right|\right)\right)\right],
\end{aligned}
$$


where

$$
\begin{array}{ll}
V_{\mu}\left(\tilde{a}_{i j}^{\sigma(k)}\right)^{*}=\frac{\left(\underline{a}_{i j}^{\sigma(k)}+4 a_{i j}^{\sigma(k)}+\bar{a}_{i j}^{\sigma(k)}\right) \omega_{\tilde{a}_{i j}^{\sigma(k)}}}{6 a^{*}}, & V_{\mu}\left(\tilde{b}_{i j}^{\sigma(k)}\right)^{*}=\frac{\left(\underline{b}_{i j}^{\sigma(k)}+4 b_{i j}^{\sigma(k)}+\bar{b}_{i j}^{\sigma(k)}\right) \omega_{\tilde{b}_{i j}^{\sigma(k)}}}{6 b^{*}}, \\
V_{v}\left(\tilde{a}_{i j}^{\sigma(k)}\right)^{*}=\frac{\left(\underline{a}_{i j}^{\sigma(k)}+4 a_{i j}^{\sigma(k)}+\bar{a}_{i j}^{\sigma(k)}\right)\left(1-\mu_{\tilde{a}_{i j}^{\sigma(k)}}\right)}{6 a^{*}}, & V_{v}\left(\tilde{b}_{i j}^{\sigma(k)}\right)^{*}=\frac{\left(\underline{b}_{i j}^{\sigma(k)}+4 b_{i j}^{\sigma(k)}+\bar{b}_{i j}^{\sigma(k)}\right)\left(1-\mu_{\tilde{b}_{i j}^{\sigma(k)}}\right)}{6 b^{*}}, \\
A_{\mu}\left(\tilde{a}_{i j}^{\sigma(k)}\right)^{*}=\frac{\left(\bar{a}_{i j}^{\sigma(k)}-\underline{a}_{i j}^{\sigma(k)}\right) \omega_{\tilde{a}_{i j}^{\sigma(k)}}}{3 a^{*}}, & A_{\mu}\left(\tilde{b}_{i j}^{\sigma(k)}\right)^{*}=\frac{\left(\bar{b}_{i j}^{\sigma(k)}-\underline{b}_{i j}^{\sigma(k)}\right) \omega_{\tilde{b}_{i j}^{\sigma(k)}}}{3 b^{*}}, \\
A_{v}\left(\tilde{a}_{i j}^{\sigma(k)}\right)^{*}=\frac{\left(\bar{a}_{i j}^{\sigma(k)}-\underline{a}_{i j}^{\sigma(k)}\right)\left(1-\mu_{\tilde{a}_{i j}^{\sigma(k)}}\right)}{3 a^{*}}, & A_{v}\left(\tilde{b}_{i j}^{\sigma(k)}\right)^{*}=\frac{\left(\bar{b}_{i j}^{\sigma(k)}-\underline{b}_{i j}^{\sigma(k)}\right)\left(1-\mu_{\tilde{b}_{i j}^{\sigma(k)}}\right)}{3 b^{*}},
\end{array}
$$

$l_{x_{i}}=\max _{\mathbf{q} \in I}\left\{l\left(h_{q}^{\prime}\left(x_{i}\right)\right)\right\}, I=\{1,2, \ldots, m\}, 0 \leqslant \lambda \leqslant 1$, and $h_{k}\left(x_{j}\right)^{\sigma(k)}=\bigcup_{i}\left(\left(\underline{a}_{i j}^{\sigma(k)}, a_{i j}^{\sigma(k)}, \bar{a}_{i j}^{\sigma(k)}\right) ; \omega_{\tilde{a}_{i j}}, \mu_{\tilde{a}_{i j}}\right)$ and $h_{t}\left(x_{j}\right)^{\sigma(k)}=\bigcup_{i}\left(\left(\underline{b}_{i j}^{\sigma(k)}, a_{i j}^{\sigma(k)}, \bar{b}_{i j}^{\sigma(k)}\right) ; \omega_{\tilde{b}_{i j}^{\sigma(k)}}, \mu_{\tilde{b}_{i j}^{\sigma(k)}}\right)$ are the jth values in $h_{k}\left(x_{j}\right)$ and $h_{t}\left(x_{j}\right)$, respectively, $a^{*}$ and $b^{*}$ are standardized constants.

Definition 4.20. Let $h_{k}^{\prime}$ and $h_{t}^{\prime}$ be two hesitant triangular intuitionistic fuzzy sets on $X=\left\{x_{1}, x_{2}, \ldots, x_{n}\right\}$, then the distance measure between $h_{k}^{\prime}$ and $h_{t}^{\prime}$ is defined as $d\left(h_{k}^{\prime}, h_{t}^{\prime}\right)$, which satisfies the following properties:

(1) $0 \leqslant \mathrm{~d}\left(\mathrm{~h}_{\mathrm{k}}^{\prime}, \mathrm{h}_{\mathrm{t}}^{\prime}\right) \leqslant 1$;

(2) $d\left(h_{k}^{\prime}, h_{t}^{\prime}\right)=0$ if and only if $h_{k}^{\prime}=h_{t}^{\prime}$;

(3) $d\left(h_{k}^{\prime}, h_{t}^{\prime}\right)=d\left(h_{t}^{\prime}, h_{k}^{\prime}\right)$.

Theorem 4.21. $\mathrm{d}_{\text {hth }}$ and $\mathrm{d}_{\text {phth }}$ are distance measures.

Proof. As $d_{h t h}$ is a particular case of $d_{\text {phth }}$, we only give the proof of $d_{\text {phth }}$.

Assume that $h_{k}^{\prime}$ and $h_{t}^{\prime}$ are two hesitant triangular intuitionistic fuzzy sets, based on Definition 4.20,

(1) and (3) are straightforward. Below let us prove $d\left(h_{k}^{\prime}, h_{t}^{\prime}\right)=0$ if and only if $h_{k}^{\prime}=h_{t}^{\prime}$.

Obviously, when $h_{k}^{\prime}=h_{t}^{\prime}, d\left(h_{k}^{\prime}, h_{t}^{\prime}\right)=0$. On the contrary, when $d\left(h_{k}^{\prime}, h_{t}^{\prime}\right)=0$, we have $u\left(h_{k}^{\prime}\left(x_{j}\right)\right)-$ $u\left(h_{t}^{\prime}\left(x_{j}\right)\right)=0, v_{\mu}\left(\tilde{a}_{i j}^{\sigma(k)}\right)^{*}-V_{\mu}\left(\tilde{b}_{i j}^{\sigma(k)}\right)^{*}=0, v_{v}\left(\tilde{a}_{i j}^{\sigma(k)}\right)^{*}-v_{v}\left(\tilde{b}_{i j}^{\sigma(k)}\right)^{*}=0, A_{\mu}\left(\tilde{a}_{i j}^{\sigma(k)}\right)^{*}-A_{\mu}\left(\tilde{b}_{i j}^{\sigma(k)}\right)^{*}=0$ and $A_{v}\left(\tilde{a}_{i j}^{\sigma(k)}\right)^{*}-A_{v}\left(\tilde{b}_{i j}^{\sigma(k)}\right)^{*}=0$, then $h_{k}^{\prime}=h_{t}^{\prime}$.

This completes the proof.

Theorem 4.22. If $\mathrm{h}_{\mathrm{s}}^{\prime}, \mathrm{h}_{\mathrm{t}}^{\prime}, \mathrm{h}_{\mathrm{q}}^{\prime}$ are three HTIFSs, then $\mathrm{d}\left(\mathrm{h}_{\mathrm{s}}^{\prime}, \mathrm{h}_{\mathrm{q}}^{\prime}\right) \leqslant \mathrm{d}\left(\mathrm{h}_{\mathrm{s}}^{\prime}, \mathrm{h}_{\mathrm{t}}^{\prime}\right)+\mathrm{d}\left(\mathrm{h}_{\mathrm{t}}^{\prime}, \mathrm{h}_{\mathrm{q}}^{\prime}\right)$ for $\mathrm{d}_{\text {hth }}$ and $\mathrm{d}_{\text {phth }}$.

Proof. Now we give the proof of the case $d_{\text {phth }}$. Assume

$$
h_{s}^{\prime}=\bigcup_{i}\left(\left(\underline{s}_{i j}, s_{i j}, \bar{s}_{i j}\right) ; \omega_{\tilde{s}_{i j}}, \mu_{\tilde{s}_{i j}}\right), \quad h_{t}=\bigcup_{i}\left(\left(\underline{t}_{i j}, t_{i j}, \bar{t}_{i j}\right) ; \omega_{\tilde{t}_{i j}}, \mu_{\tilde{t}_{i j}}{ }^{\prime}, \text { and } h_{q}^{\prime}=\bigcup_{i}\left(\left(\underline{q}_{i j}, q_{i j}, \bar{q}_{i j}\right) ; \omega_{\tilde{q}_{i j}}, \mu_{\tilde{q}_{i j}}\right)\right.
$$

are three HTIFS, as

$$
\begin{gathered}
\left|u\left(h_{s}^{\prime}\left(x_{j}\right)\right)-u\left(h_{q}^{\prime}\left(x_{j}\right)\right)\right| \leqslant\left|u\left(h_{s}^{\prime}\left(x_{j}\right)\right)-u\left(h_{t}^{\prime}\left(x_{j}\right)\right)\right|+\left|u\left(h_{t}^{\prime}\left(x_{j}\right)\right)-u\left(h_{q}^{\prime}\left(x_{j}\right)\right)\right|, \\
\left|V_{\mu}\left(\tilde{s}_{i j}^{\sigma(k)}\right)^{*}-V_{\mu}\left(\tilde{t}_{i j}^{\sigma(k)}\right)^{*}\right| \leqslant\left|V_{\mu}\left(\tilde{s}_{i j}^{\sigma(k)}\right)^{*}-V_{\mu}\left(\tilde{q}_{i j}^{\sigma(k)}\right)^{*}\right|+\left|V_{\mu}\left(\tilde{q}_{i j}^{\sigma(k)}\right)^{*}-V_{\mu}\left(\tilde{t}_{i j}^{\sigma(k)}\right)^{*}\right|, \\
\left|V_{v}\left(\tilde{s}_{i j}^{\sigma(k)}\right)^{*}-V_{v}\left(\tilde{t}_{i j}^{\sigma(k)}\right)^{*}\right| \leqslant\left|V_{v}\left(\tilde{s}_{i j}^{\sigma(k)}\right)^{*}-V_{v}\left(\tilde{q}_{i j}^{\sigma(k)}\right)^{*}\right|+\left|V_{v}\left(\tilde{q}_{i j}^{\sigma(k)}\right)^{*}-V_{v}\left(\tilde{t}_{i j}^{\sigma(k)}\right)^{*}\right|, \\
\left|A_{\mu}\left(\tilde{s}_{i j}^{\sigma(k)}\right)^{*}-A_{\mu}\left(\tilde{t}_{i j}^{\sigma(k)}\right)^{*}\right| \leqslant\left|A_{\mu}\left(\tilde{s}_{i j}^{\sigma(k)}\right)^{*}-A_{\mu}\left(\tilde{q}_{i j}^{\sigma(k)}\right)^{*}\right|+\left|A_{\mu}\left(\tilde{q}_{i j}^{\sigma(k)}\right)^{*}-A_{\mu}\left(\tilde{t}_{i j}^{\sigma(k)}\right)^{*}\right|, \\
\left|A_{v}\left(\tilde{s}_{i j}^{\sigma(k)}\right)^{*}-A_{v}\left(\tilde{t}_{i j}^{\sigma(k)}\right)^{*}\right| \leqslant\left|A_{v}\left(\tilde{s}_{i j}^{\sigma(k)}\right)^{*}-A_{v}\left(\tilde{q}_{i j}^{\sigma(k)}\right)^{*}\right|+\left|A_{v}\left(\tilde{\mathrm{q}}_{i j}^{\sigma(k)}\right)^{*}-A_{v}\left(\tilde{t}_{i j}^{\sigma(k)}\right)^{*}\right|,
\end{gathered}
$$

we have $d_{\text {phth }}\left(h_{s}^{\prime}, h_{q}^{\prime}\right) \leqslant d_{\text {phth }}\left(h_{s}^{\prime}, h_{t}^{\prime}\right)+d_{\text {phth }}\left(h_{t}^{\prime}, h_{q}^{\prime}\right)$. And the proof of the case $d_{h t h}$ is similar to that of $\mathrm{d}_{\text {phth. }}$. 
Next, we consider both the different preferences between the influences of the hesitance degree and the values and ambiguities of TIFNs and the weight of each element $x \in X$, then the weighted distance measure with preferences is given as follows:

Definition 4.23. Let $h_{k}^{\prime}, h_{t}^{\prime}$ be two HTIFSs on $X=\left\{x_{1}, x_{2}, \ldots x_{n}\right\}$ and $h_{k}^{\prime}\left(x_{j}\right)=\bigcup_{i}\left(\left(\underline{a}_{i j}, a_{i j}, \bar{a}_{i j}\right) ; \omega_{\tilde{a}_{i j}}, \mu_{\tilde{a}_{i j}}\right)$, $h_{t}^{\prime}\left(x_{j}\right)=\bigcup_{i}\left(\left(\underline{b}_{i j}, a_{i j}, \bar{b}_{i j}\right) ; \omega_{\tilde{b}_{i j}}, \mu_{\tilde{b}_{i j}}\right)$ be two HTIFEs, $k, t=1,2, \ldots, m$, then the distance is defined as

$$
\begin{aligned}
d_{\text {wphth }}\left(h_{1}^{\prime}, h_{2}^{\prime}\right)= & \sum_{j=1}^{n} \omega_{j}\left[\alpha\left|u\left(h_{k}^{\prime}\left(x_{j}\right)\right)-u\left(h_{t}^{\prime}\left(x_{j}\right)\right)\right|+\frac{1-\alpha}{2 l_{x_{j}}} \sum_{i=1}^{l_{x_{j}}}\left(\lambda \left(\left|V_{\mu}\left(\tilde{a}_{i j}^{\sigma(k)}\right)^{*}-V_{\mu}\left(\tilde{b}_{i j}^{\sigma(k)}\right)^{*}\right|+\mid V_{v}\left(\tilde{a}_{i j}^{\sigma(k)}\right)^{*}\right.\right.\right. \\
& \left.\left.\left.-V_{v}\left(\tilde{b}_{i j}^{\sigma(k)}\right)^{*} \mid\right)+(1-\lambda)\left(\left|A_{\mu}\left(\tilde{a}_{i j}^{\sigma(k)}\right)^{*}-A_{\mu}\left(\tilde{b}_{i j}^{\sigma(k)}\right)^{*}\right|+\left|A_{v}\left(\tilde{a}_{i j}^{\sigma(k)}\right)^{*}-A_{v}\left(\tilde{b}_{i j}^{\sigma(k)}\right)^{*}\right|\right)\right)\right],
\end{aligned}
$$

where

$$
\begin{array}{ll}
V_{\mu}\left(\tilde{a}_{i j}^{\sigma(k)}\right)^{*}=\frac{\left(\underline{a}_{i j}^{\sigma(k)}+4 a_{i j}^{\sigma(k)}+\bar{a}_{i j}^{\sigma(k)}\right) \omega_{\tilde{a}_{i j}^{\sigma(k)}}}{6 a^{*}}, \quad V_{\mu}\left(\tilde{b}_{i j}^{\sigma(k)}\right)^{*}=\frac{\left(\underline{b}_{i j}^{\sigma(k)}+4 b_{i j}^{\sigma(k)}+\bar{b}_{i j}^{\sigma(k)}\right) \omega_{\tilde{b}_{i j}^{\sigma(k)}}}{6 b^{*}}, \\
V_{v}\left(\tilde{a}_{i j}^{\sigma(k)}\right)^{*}=\frac{\left(\underline{a}_{i j}^{\sigma(k)}+4 a_{i j}^{\sigma(k)}+\bar{a}_{i j}^{\sigma(k)}\right)\left(1-\mu_{\tilde{a}_{i j}^{\sigma(k)}}\right)}{6 a^{*}}, & V_{v}\left(\tilde{b}_{i j}^{\sigma(k)}\right)^{*}=\frac{\left(\underline{b}_{i j}^{\sigma(k)}+4 b_{i j}^{\sigma(k)}+\bar{b}_{i j}^{\sigma(k)}\right)\left(1-\mu_{\tilde{b}_{i j}^{\sigma(k)}}\right)}{6 b^{*}}, \\
A_{\mu}\left(\tilde{a}_{i j}^{\sigma(k)}\right)^{*}=\frac{\left(\bar{a}_{i j}^{\sigma(k)}-\underline{a}_{i j}^{\sigma(k)}\right) \omega_{\tilde{a}_{i j}^{\sigma(k)}}^{\sigma(k)}}{3 a^{*}}, & A_{\mu}\left(\tilde{b}_{i j}^{\sigma(k)}\right)^{*}=\frac{\left(\bar{b}_{i j}^{\sigma(k)}-\underline{b}_{i j}^{\sigma(k)}\right) \omega_{\tilde{b}_{i j}^{\sigma(k)}}}{3 b^{*}}, \\
A_{v}\left(\tilde{a}_{i j}^{\sigma(k)}\right)^{*}=\frac{\left(\bar{a}_{i j}^{\sigma(k)}-\underline{a}_{i j}^{\sigma(k)}\right)\left(1-\mu_{\tilde{a}_{i j}^{\sigma(k)}}\right)}{3 a^{*}}, & A_{v}\left(\tilde{b}_{i j}^{\sigma(k)}\right)^{*}=\frac{\left(\bar{b}_{i j}^{\sigma(k)}-\underline{b}_{i j}^{\sigma(k)}\right)\left(1-\mu_{\tilde{b}_{i j}^{\sigma(k)}}\right)}{3 b^{*}},
\end{array}
$$

$l_{x_{i}}=\max _{q \in I}\left\{l\left(h_{q}^{\prime}\left(x_{i}\right)\right)\right\}, I=\{1,2, \ldots, m\}, 0 \leqslant \lambda \leqslant 1$, and $h_{k}\left(x_{j}\right)^{\sigma(k)}=\bigcup_{i}\left(\left(\underline{a}_{i j}^{\sigma(k)}, a_{i j}^{\sigma(k)}, \bar{a}_{i j}^{\sigma(k)}\right) ; \omega_{\tilde{a}_{i j}}, \mu_{\tilde{a}_{i j}}\right)$ and $h_{t}\left(x_{j}\right)^{\sigma(k)}=\bigcup_{i}\left(\left(\underline{b}_{i j}^{\sigma(k)}, a_{i j}^{\sigma(k)}, \bar{b}_{i j}^{\sigma(k)}\right) ; \omega_{\tilde{b}_{i j}^{\sigma(k)}}, \mu_{\tilde{b}_{i j}^{\sigma(k)}}\right)$ are the jth values in $h_{k}\left(x_{j}\right)$ and $h_{t}\left(x_{j}\right)$, respectively, $a^{*}$ and $b^{*}$ are standardized constants.

Assume that if $\omega_{1}=\omega_{2}=\ldots=\omega_{n}=\frac{1}{n}$, then $d_{w p h t h}\left(h_{1}^{\prime}, h_{2}^{\prime}\right)$ is reduced to $d_{\text {phth }}\left(h_{1}^{\prime}, h_{2}^{\prime}\right)$.

Theorem 4.24. $\mathrm{d}_{\text {wphth }}$ is a distance measure.

Proof. Based on Theorem 4.21, it is obvious.

\section{Several methods to MADM problems with hesitant triangular intuitionistic fuzzy information}

The traditional aggregation operations and the distance measures are of great use in MADM problems. In this section, we give three methods to MADM problems with hesitant triangular intuitionistic fuzzy information. The following assumptions are used to represent the MADM problems for potential evaluation of emerging technology commercialization with hesitant triangular intuitionistic fuzzy information. For a multiple decision making problem with hesitant triangular intuitionistic fuzzy information, let $X=\left(X_{1}, X_{2}, \ldots, X_{m}\right)$ be a discrete set of alternatives, and let $G=\left(G_{1}, G_{2}, \ldots, G_{n}\right)$ be a finite set of attributes, $\omega=\left(\omega_{1}, \omega_{2}, \ldots, \omega_{n}\right)^{\top}$ is the weighting vector of the attribute $G_{j}(j=1,2, \ldots, n)$, where $\omega_{j} \in[0,1], \sum_{j=1}^{n} \omega_{j}=1$. If the decision makers provide several triangular intuitionistic fuzzy values for the alternative $X_{i}$ under the attribute $G_{j}$, these values can be regarded as hesitant triangular intuitionistic fuzzy element $\tilde{h}_{(i j)}^{\prime}$. Suppose that $H=\left(\tilde{h}_{(i j)}^{\prime}\right)_{m n}$ is the hesitant triangular intuitionistic fuzzy decision matrix.

Now we present three methods to the MADM problems with hesitant triangular intuitionistic fuzzy information as follows: 


\section{METHOD 1.}

Step 1. We utilize the decision information given in matrix $\mathrm{H}$, and the HTIFWA (4.1), HTIFWG (4.3), HTIFOWA (4.2) and HTIFOWG (4.4) operators to aggregate the hesitant triangular intuitionistic fuzzy elements $\tilde{h}_{i}(i=1,2, \ldots, m)$ of the alternative $X_{i}$.

Step 2. Calculate the scores $S\left(\tilde{h}_{i}\right)$ of the hesitant triangular intuitionistic fuzzy elements $\tilde{h}_{\mathfrak{i}}(i=1,2, \ldots, \mathrm{m})$ of the alternative $X_{i}$ by Definition 4.4.

Step 3. Rank all the alternatives $X_{i}(i=1,2, \ldots, m)$ based on the rank of $\tilde{h}_{i}$ and select the best one(s).

Step 4. End.

\section{METHOD 2.}

Step 1. We calculate the values of the membership degree and the non-membership degree of every triangular intuitionistic number of the HTIFEs $\mu_{\left(\tilde{a}_{i}\right)}^{*}$ and $v_{\left(\tilde{a}_{i}\right)}^{*}$, respectively. Then we can obtain the standardized hesitant triangular intuitionistic fuzzy information matrix $H^{\prime}$ by using $\tilde{H}_{E(x)}^{\prime}=\bigcup_{i}\left\{\left(\mu_{\left(\tilde{a}_{i}\right)}^{*}, v_{\left(\tilde{a}_{i}\right)}^{*}\right\}(i=\right.$ $\left.1,2, \ldots, l\left(\tilde{H}^{\prime}\right)\right)$ instead of $\tilde{h}_{E}^{\prime}(x)=\bigcup_{i}\left(\left(\underline{a}_{i}, a_{i}, \bar{a}_{i}\right) ; \omega_{i}, u_{i}\right)\left(i=1,2, \ldots, l\left(\tilde{h}^{\prime}\right)\right)$.

Step 2. We utilize the decision information given in matrix $\mathrm{H}^{\prime}$, and the S-HTIFWA (4.5), S-HTIFWG (4.7), S-HTIFOWA (4.6) and S-HTIFOWG (4.8) operators to aggregate the hesitant triangular intuitionistic fuzzy elements $\tilde{H}_{i}(i=1,2, \ldots, m)$ of the alternative $X_{i}$.

Step 3. Calculate the scores $S\left(\tilde{H}_{i}\right)$ of the hesitant triangular intuitionistic fuzzy elements $\tilde{H}_{i}(i=1,2, \ldots, m)$ of the alternative $X_{i}$ by Definition 4.9.

Step 4. Rank all the alternatives $X_{i}(i=1,2, \ldots, m)$ based on the rank of $\tilde{H}_{i}$ and select the best one(s).

Step 5. End.

\section{METHOD 3.}

Step 1. We can use the equation

$$
\begin{aligned}
\mathrm{d}_{w p h t h}\left(h_{k}^{\prime}, h_{t}^{\prime}\right)= & \sum_{j=1}^{n} \omega_{j}\left[\alpha\left|u\left(h_{k}^{\prime}\left(x_{j}\right)\right)-u\left(h_{t}^{\prime}\left(x_{j}\right)\right)\right|+\frac{1-\alpha}{2 l_{x_{j}}} \sum_{i=1}^{l_{x_{j}}}\left(\lambda \left(\left|V_{\mu}\left(\tilde{a}_{i j}^{\sigma(k)}\right)^{*}-V_{\mu}\left(\tilde{b}_{i j}^{\sigma(k)}\right)^{*}\right|+\mid V_{v}\left(\tilde{a}_{i j}^{\sigma(k)}\right)^{*}\right.\right.\right. \\
& \left.\left.\left.-V_{v}\left(\tilde{b}_{i j}^{\sigma(k)}\right)^{*} \mid\right)+(1-\lambda)\left(\left|A_{\mu}\left(\tilde{a}_{i j}^{\sigma(k)}\right)^{*}-A_{\mu}\left(\tilde{b}_{i j}^{\sigma(k)}\right)^{*}\right|+\left|A_{v}\left(\tilde{a}_{i j}^{\sigma(k)}\right)^{*}-A_{v}\left(\tilde{b}_{i j}^{\sigma(k)}\right)^{*}\right|\right)\right)\right],
\end{aligned}
$$

to calculate the distance measure $d_{i}$ between the ideal alterative and the alterative $X_{i}$ based on Definition 4.23 .

Step 2. Rank all the alteratives $X_{i}(i=1,2, \ldots, m)$ based on the rank of $\tilde{H}_{i}$ and select the best one(s) based on the distance measure $d_{i}$.

Step 3. End.

\section{Numerical example}

Thus, in this section we present a numerical example for supplier selection in supply chain management problems with hesitant triangular intuitionistic fuzzy information in order to illustrate the methods proposed in this paper. Let us suppose there are four alternatives (prospect supplier) $X_{i}(i=1,2,3,4)$ for three attributes $G_{j}(j=1,2,3)$ with product quality $\left(G_{1}\right)$, service $\left(G_{2}\right)$, ad price $\left(G_{3}\right)$. And the hesitant triangular intuitionistic fuzzy information matrix is shown in Table 1. 
Table 1: Hesitant triangular intuitionistic fuzzy information matrix.

\begin{tabular}{|c|c|c|c|}
\hline & $\mathrm{G}_{1}$ & $\mathrm{G}_{2}$ & $\mathrm{G}_{3}$ \\
\hline$A_{1}$ & $\{((6,8,8) ; 0,6,0.3)\}$ & $\{((6,7,8) ; 0.7,0.2)\}$ & $\{((6,7,8) ; 0.7,0.2)\}$ \\
\hline$A_{2}$ & $\{((4,6,8) ; 0,5,0.3)\}$ & $\begin{array}{c}\{((4,5,6) ; 0.7,0.2), \\
((3,5,7) ; 0.5,0.3), \\
((4,5,6), 0.5,0.3)\}\end{array}$ & $\begin{array}{l}\{((4,6,8) ; 0.6,0.3), \\
((6,7,9) ; 0.6,0.3)), \\
((6,7,8), 0.6,0.3)\}\end{array}$ \\
\hline$A_{3}$ & $\begin{array}{c}\{((3,4,4) ; 0,6,0.3), \\
(4,4,6) ; 0.5,0.3), \\
((4,6,8) ; 0.5,0.2)\}\end{array}$ & $\{((2,4,6) ; 0.7,0.3)\}$ & $\{((4,6,6) ; 0.5,0.2))\}$ \\
\hline $\mathrm{A}_{4}$ & $\begin{array}{c}\{((6,7,8) ; 0,6,0.3), \\
(6,8,9) ; 0.5,0.3)\}\end{array}$ & $\{((4,5,6) ; 0.6,0.2)\}$ & $\{((6,6,8) ; 0.8,0.1),((2,6,8) ; 0.4,0.1))\}$ \\
\hline
\end{tabular}

In the table, the total score of decision makers is 10 . And the attribute weights is known as follows: $\omega=(0.4,0.2,0.4)$.

\section{METHOD 1.}

Step 1. We utilize the decision information given in matrix H, and the HTIFWA (4.1) and HTIFWG (4.3) operators to aggregate the hesitant triangular intuitionistic fuzzy elements $\tilde{h}_{i}(i=1,2, \ldots, m)$ of the alternative $X_{i}$. Take alternative $A_{4}$ for an example, we have

$$
\begin{aligned}
\operatorname{HTIFWA}\left(\tilde{\mathrm{h}}_{1}^{\prime}, \tilde{\mathrm{h}}_{2}^{\prime}, \ldots, \tilde{\mathrm{h}}_{\mathrm{n}}^{\prime}\right)= & \sum_{j=1}^{n} w_{j} \tilde{\mathrm{h}}_{j}^{\prime} \\
= & \bigcup_{i}\left\{\left(\left(\sum_{j=1}^{n} w_{j} \underline{a}_{i j}, \sum_{j=1}^{n} w_{j} a_{i j}, \sum_{j=1}^{n} w_{i j} \bar{a}_{j}\right) ; \min _{j} w_{i j}, \max _{j} u_{i j}\right)\right\} \\
= & \{((5.6,6.2,7.6) ; 0.6,0.3),((4,6.2,7.6) ; 0.4,0.3),((5.6,6.6,8) ; 0.5,0.3), \\
& ((4,6.6,8) ; 0.4,0.3)\}, \\
\operatorname{HTIFWG}\left(\tilde{h}_{1}^{\prime}, \tilde{h}_{2}^{\prime}, \ldots, \tilde{h}_{n}^{\prime}\right)= & \prod_{j=1}^{n} \tilde{h}_{j}^{\prime w_{j}} \\
= & \bigcup_{i}\left\{\left(\left(\prod_{j=1}^{n} \underline{a}_{i j}^{w_{j}}, \prod_{j=1}^{n} a_{i j}^{w_{j}}, \prod_{j=1}^{n} \bar{a}_{i j}^{w_{j}}\right) ; \min _{j} w_{i j}, \max _{j} u_{i j}\right)\right\} \\
= & \{((5.5326,6.1531,7.5527) ; 0.6,0.3),((3.5652,6.1531,7.5527) ; 0.4,0.3), \\
& ((5.5326,6.4907,7.9170) ; 0.5,0.3),((3.5652,6.4907,7.9170) ; 0.4,0.3)\} .
\end{aligned}
$$

Step 2 and Step 3. Calculate the scores $S\left(\tilde{h}_{i}\right)$ of the hesitant triangular intuitionistic fuzzy elements $\tilde{h}_{i}(i=1,2, \ldots, m)$ of the alternative $X_{i}$ by Definition 4.4 . Rank all the alternatives $X_{i}(i=1,2, \ldots, m)$ based on the rank of $\tilde{h}_{i}$. The results are listed as Table 2 .

Table 2: Results of $S\left(\tilde{h}_{i}\right)$ and rankings.

\begin{tabular}{|l|c|c|c|c|c|}
\hline & $A_{1}$ & $A_{2}$ & $A_{3}$ & $A_{4}$ & Rankings \\
\hline HTIFWA & 0.2160 & 0.122 & 0.098 & 0.1125 & $A_{1} \succ A_{2} \succ A_{4} \succ A_{3}$ \\
HTIFWG & 0.2158 & 0.1210 & 0.0999 & 0.1106 & $A_{1} \succ A_{2} \succ A_{4} \succ A_{3}$ \\
\hline
\end{tabular}




\section{METHOD 2.}

Step 1. We calculate the values of the membership degree and the non-membership degree of every triangular intuitionistic number of the HTIFEs $\mu_{\left(\tilde{a}_{i}\right)}^{*}$ and $v_{\left(\tilde{a}_{i}\right)}^{*}$, respectively. Then we can obtain the standardized hesitant triangular intuitionistic fuzzy information matrix $\mathrm{H}^{\prime}$ as Table 3.

Table 3: The standardized hesitant triangular intuitionistic fuzzy information matrix $\mathrm{H}^{\prime}$.

\begin{tabular}{|c|c|c|c|}
\hline & $\mathrm{G}_{1}$ & $\mathrm{G}_{2}$ & $\mathrm{G}_{3}$ \\
\hline$A_{1}$ & $\{(0.3539,0.4128)\}$ & $\{(0.3267,0.3733)\}$ & $\{(0.3267,0.3733)\}$ \\
\hline$A_{2}$ & $\{(0.25,0.35)\}$ & $\begin{array}{c}\{(0.2333,0.2667), \\
(0.2083,0.2917), \\
(0.2083,0.2917)\}\end{array}$ & $\begin{array}{c}\{(0.2769,0.3231), \\
(0.3308,0.3859), \\
(0.3231,0.3769)\}\end{array}$ \\
\hline$A_{3}$ & $\begin{array}{c}\{(0.1769,0.2064), \\
(0.1856,0.2528), \\
(0.2308,0.3692)\}\end{array}$ & $\{(0.2,0.2)\}$ & $\{(0.2179,0.3487)\}$ \\
\hline$A_{4}$ & $\begin{array}{r}\{(0.3231,0.3769), \\
(0.3264,0.4569)\}\end{array}$ & $\{(0.2143,0.2857)\}$ & $\{(0.298,0.3353),(0.1744,0.3923)\}$ \\
\hline
\end{tabular}

Step 2. We utilize the decision information given in matrix $\mathrm{H}^{\prime}$, and the S-HTIFWA (4.5) and S-HTIFWG (4.7) operators to aggregate the hesitant triangular intuitionistic fuzzy elements $\tilde{H}_{i}(i=1,2, \ldots, m)$ of the alternative $X_{i}$. Take $A_{4}$ for an example, we have

$$
\begin{aligned}
\operatorname{S-HTIFWA}\left(\tilde{\mathrm{H}}_{1}^{\prime}, \tilde{\mathrm{H}}_{2}^{\prime}, \ldots, \tilde{\mathrm{H}}_{\mathfrak{n}}^{\prime}\right) & =\oplus_{j=1}^{n} w_{j} \tilde{\mathrm{H}}_{j}^{\prime} \\
& =\bigcup_{i}\left\{\left(1-\prod_{j=1}^{n}\left(1-\mu_{\left(\tilde{a}_{i j}\right)}^{*}\right)^{w_{j}}, 1-\prod_{j=1}^{n}\left(1-v_{\left(\tilde{a}_{i j}\right)}^{*}\right)^{w_{j}}\right)\right\} \\
& =\{(0.2924,0.3429),(0.2450,0.3660),(0.2938,0.3780),(0.2464,0.3999)\}, \\
\operatorname{S-HTIFWG}\left(\tilde{\mathrm{H}}_{1}^{\prime}, \tilde{\mathrm{H}}_{2}^{\prime}, \ldots, \tilde{\mathrm{H}}_{\mathfrak{n}}^{\prime}\right) & =\otimes_{j=1}^{n} w_{j} \tilde{\mathrm{H}}_{j}^{\prime} \\
& =\bigcup_{i}\left\{\left(\prod_{j=1}^{n}\left(\mu_{\left(\tilde{a}_{i j}\right)}^{*}\right)^{w_{j}}, \prod_{j=1}^{n}\left(v_{\left(\tilde{a}_{i j}\right)}^{*}\right)^{w_{j}}\right)\right\} \\
& =\{(0.2882,0.2530),(0.2326,0.3623),(0.2893,0.3675),(0.2335,0.3913)\} .
\end{aligned}
$$

Step 3 and Step 4. Calculate the scores $S\left(\tilde{H}_{i}\right)$ of the hesitant triangular intuitionistic fuzzy elements $\tilde{H}_{i}(i=1,2, \ldots, m)$ of the alternative $X_{i}$ by Definition 4.9. Rank all the alternatives $X_{i}(i=1,2, \ldots, m)$ based on the rank of $\tilde{H}_{i}$ and select the best one(s). The results are listed as Table 4.

Table 4: Results of $S\left(\tilde{h}_{i}\right)$ and rankings.

\begin{tabular}{|l|c|c|c|c|c|}
\hline & $A_{1}$ & $A_{2}$ & $A_{3}$ & $A_{4}$ & Rankings \\
\hline S-HTIFWA & -0.0517 & -0.0738 & -0.0871 & -0.1023 & $A_{1} \succ A_{2} \succ A_{3} \succ A_{4}$ \\
S-HTIFWG & -0.0513 & -0.0752 & -0.0772 & -0.1045 & $A_{1} \succ A_{2} \succ A_{3} \succ A_{4}$ \\
\hline
\end{tabular}

\section{METHOD 3.}

Suppose that the ideal alternative is the hesitant triangular intuitionistic fuzzy number $E_{*}=\{((10,10$, $10) ; 1,0),((10,10,10) ; 1,0),((10,10,10) ; 1,0)\}$, which is seen as a special HTIFS. Then, we can select the best alternative by calculating the distance between each alternative and the ideal alternative. And we utilize the distance measure to select the most desirable supplier. In order to facilitate the analysis, we adopt parameters $\lambda=0.5$ and $\alpha=0,0.01,0.1,0.5,0.9$. The results are listed as Table 5 . 
Table 5: Results of $d_{w p h t h}$ and rankings $(\lambda=0.5)$.

\begin{tabular}{|c|c|c|c|c|c|}
\hline & $A_{1}$ & $A_{2}$ & $A_{3}$ & $A_{4}$ & Rankings \\
\hline$\alpha=0$ & 0.2665 & 0.3428 & 0.3719 & 0.3144 & $A_{1} \succ A_{4} \succ A_{2} \succ A_{3}$ \\
$\alpha=0.01$ & 0.2705 & 0.3420 & 0.3666 & 0.3103 & $A_{1} \succ A_{4} \succ A_{2} \succ A_{3}$ \\
$\alpha=0.1$ & 0.3065 & 0.3352 & 0.3697 & 0.2942 & $A_{4} \succ A_{1} \succ A_{2} \succ A_{3}$ \\
$\alpha=0.5$ & 0.4666 & 0.3047 & 0.3831 & 0.2227 & $A_{4} \succ A_{2} \succ A_{3} \succ A_{1}$ \\
$\alpha=0.9$ & 0.6267 & 0.2743 & 0.3966 & 0.1512 & $A_{4} \succ A_{2} \succ A_{3} \succ A_{1}$ \\
\hline
\end{tabular}

It is worth mentioning that Method 1 is simple and effective under hesitant triangular intuitionistic fuzzy environments, and the key to this approach lies in the expression of the distance measure $d_{w p h t h}$. Inspired by Li et al. [8], the distance measure not only takes the hesitance degree, the values and ambiguities of TIFNs into account, but also considers the different preferences of the decision makers. In other words, we extend the distance measure from hesitant fuzzy sets to hesitant triangular intuitionistic fuzzy sets, thus, we can deal with the situations without giving properly the imprecise or uncertain decision information in the real-world environments assigning exact values. On the other hand, the distance measure, what considers the effect of the hesitance degree of HTIFS, is meaningful. When $\alpha=0$, the results and the rankings are almost different from that of $\alpha=0.01,0.1,0.5,0.9$, for example, with the increase of parameter $\alpha, A_{1} \succ A_{4} \succ A_{2} \succ A_{3}$ is changed as $A_{4} \succ A_{1} \succ A_{2} \succ A_{3}$, and at last obtaining that $A_{4} \succ A_{2} \succ A_{3} \succ A_{1}$ in Table 5. Besides, the parameter $\lambda$ have a great effect on the results and rankings, we give the case of $\alpha=0.5$ and $\alpha=0.1,0.3,0.7,0.9$ in Table 6 . Obviously, as the parameter $\lambda$ changes, the results and rankings are different.

Table 6: Results of $d_{w p h t h}$ and rankings $(\alpha=0.5)$.

\begin{tabular}{|c|c|c|c|c|c|}
\hline & $A_{1}$ & $A_{2}$ & $A_{3}$ & $A_{4}$ & Rankings \\
\hline$\lambda=0.1$ & 0.4242 & 0.2573 & 0.3190 & 0.3837 & $A_{1} \succ A_{4} \succ A_{2} \succ A_{3}$ \\
$\lambda=0.3$ & 0.5121 & 0.3668 & 0.4455 & 0.4829 & $A_{4} \succ A_{1} \succ A_{2} \succ A_{3}$ \\
$\lambda=0.7$ & 0.7342 & 0.5855 & 0.6984 & 0.6815 & $A_{4} \succ A_{2} \succ A_{3} \succ A_{1}$ \\
$\lambda=0.9$ & 0.7751 & 0.6948 & 0.8248 & 0.7807 & $A_{1} \succ A_{4} \succ A_{2} \succ A_{3}$ \\
\hline
\end{tabular}

From the results of Method 1 or Method 2, it is easily seen that the rankings of the alternatives are the same by using two operators respectively. And the overall rankings of alternatives are slightly different between Method 1 and Method 2, and the optimal alternative is $A_{1}$. For the Method 3, the rankings of alternatives depend on the select of the parameter $\lambda$, which represents the preference of the hesitant degree and the membership values. As a whole, the three methods are basically coincident. When $\lambda=0.01$, the ranking of these three methods have little difference, and the most desirable supplier is $A_{1}$. This shows that these three methods are feasible and practical.

\subsection{Analysis of three methods}

These three methods are used to solve the problem of multiple attribute decision making based on the triangular intuitionistic fuzzy information. In order to have a good knowledge of these methods, we give some analysis and description:

1. The scope of the above three methods is different. In terms of the first method, since the operation law of the triangular intuitionistic fuzzy numbers $\tilde{a}$ and $\tilde{b}$ in Definition 3.2 is different from the sign (positive, negative) of $\tilde{a}$ and $\tilde{b}$, the aggregation operators HTIFWG and HTIFOWG are required to ensure that the value $\underline{a}$ of the hesitant triangular fuzzy element $\tilde{a}^{\prime}=((\underline{a}, a, \bar{a}) ; \omega, u)$ is positive. After that we can handle the decision making information to solve the problem. For the other two methods, the value a is free without restrictive condition. In other words, the last two methods are more widely used than the first one. As a matter of fact, the sign (positive, negative) $\underline{a}$ in the triangular intuitionistic 
fuzzy number $\tilde{a}=((\underline{a}, a, \bar{a}) ; w, u)$ in some references [15] are not taken into account. To a certain extent, the limit of the operator we set is relatively not so large.

2. The ways to solve the problem are not the same. In the first two methods, in order to figure out the problem, we compare the quantified abstract information based upon the information from the aggregating operators and then rank the alternatives through score function. The third method calculates the distance measure between the ideal alternative and the given alternative to evaluate the merits of the scheme. During the process of solving the problem, the first two methods are more complex than the third one in terms of the problem-solving steps.

3. The conditions of the above three methods are also different. The third method needs an ideal alternative to be the standard one. In this respect, the first two methods can be applied to more types of multiple attribute decision making problems than the third one.

4. In the process of solving problems, the operators' arithmetical operations in the first method is different from the second one. The operations of the second method's operators is more commonly used to apply in the hesitant fuzzy set and intuitionistic fuzzy set. But the second methods can make the fuzzy information standardization into an interval valued intuitionistic fuzzy form, which is quite complicated in computation. In the third method, the preference of the hesitant degree, the membership value, as well as the hesitance degree of HTIFE are all taken into account to reduce the error of the distance measure.

\section{Summaries}

In this paper, we aim to propose three approaches of hesitant triangular intuitionistic fuzzy sets for dealing with Multi-attribute decision making (MADM) problems. We firstly recall some basic concepts related to hesitant fuzzy sets and triangular intuitionistic fuzzy numbers and present the concepts of hesitant triangular intuitionistic fuzzy sets. Then we develop some hesitant triangular intuitionistic fuzzy aggregation operators and standardized hesitant triangular intuitionistic fuzzy aggregation operators and distance measures of hesitant triangular intuitionistic fuzzy sets. Finally, three methods of MADM problems, as well as the analysis of the comparison between the methods are proposed to illustrate their applicability and availability by an example in order to study the application of hesitant triangular intuitionistic fuzzy sets. What is worth mentioning is that we simply give some basic hesitant triangular intuitionistic fuzzy aggregation operators and standardized hesitant triangular intuitionistic fuzzy aggregation operators, hence in our future work we will investigate the operators of hesitant triangular intuitionistic fuzzy sets and their application in MADM problems.

\section{Acknowledgment}

The authors thank the editor and the referees for their valuable comments and suggestions. This research has been supported by the National Natural Science Foundation of China (11461043, 11661053) and supported partly by the Provincial Natural Science Foundation of Jiangxi, China (20142BAB201005, 20161BAB201009).

\section{References}

[1] K. T. Atanassov, Intuitionistic fuzzy sets, Fuzzy Sets and Systems, 20 (1986), 87-96. 1

[2] K. T. Atanassov, More on intuitionistic fuzzy sets, Fuzzy Sets and Systems, 33 (1989), 37-45. 1

[3] D. Dubois, H. Prade, Fuzzy sets and systems, Theory and applications, With a foreword by Lotfi A. Zadeh, Mathematics in Science and Engineering, Academic Press, Inc. [Harcourt Brace Jovanovich, Publishers], New YorkLondon, (1980). 3.1

[4] J. C. Harsanyi, Cardinal welfare, individualistic ethics, and interpersonal comparisons of utility, J. Polit. Econ., 63 (1955), 309-321. 1

[5] F. Herrera, E. Herrera-Viedma and F. Chiclana, A study of the origin and uses of the ordered weighted geometric operator in multicriteria decision making, Int. J. Intell. Syst., 18 (2003), 689-707.1 
[6] D.-F. Li, A note on "using intuitionistic fuzzy sets for fault-tree analysis on printed circuit board assembly", Microelectron. Reliab., 48 (2008), 1741. 3.1, 3.2

[7] D.-Q. Li, W.-Y. Zeng, J.-H. Li, New distance and similarity measures on hesitant fuzzy sets and their applications in multiple criteria decision making, Eng. Appl. Artif. Intell., 40 (2015), 11-16. 1

[8] D.-Q. Li, W.-Y. Zeng, Y.-B. Zhao, Note on distance measure of hesitant fuzzy sets, Inform. Sci., 321 (2015), 103-115. 1, $2,2.4,2.5,4.4,4.4,6$

[9] X. C. Liu, Entropy, distance measure and similarity measure of fuzzy sets and their relations, Fuzzy Sets and Systems, 52 (1992), 305-318. 1

[10] D. G. Park, Y. C. Kwun, J. H. Park, I. Y. Park, Correlation coefficient of interval-valued intuitionistic fuzzy sets and its application to multiple attribute group decision making problems, Math. Comput. Modelling, 50 (2009), 1279-1293. 1

[11] T. L. Saaty, The analytic hierarchy process, Planning, priority setting, resource allocation, McGraw-Hill International Book Co., New York, (1980). 1

[12] V. Torra, Hesitant fuzzy sets, Int. J. Intell. Syst., 25 (2010), 529-539. 1, 2.1, 4.3

[13] V. Torra, Y. Narukawa, On hesitant fuzzy sets and decision, in: The 18th IEEE International Conference on Fuzzy Systems, Jeju Island, Korea, (2009), 1378-1382. 1

[14] S.-P. Wan, Q.-Y. Wang, J.-Y. Dong, The extended VIKOR method for multi-attribute group decision making with triangular intuitionistic fuzzy numbers, Knowl.-Based Syst., 52 (2013), 65-77. 1, 3.2

[15] J.-Q. Wang, R.-R. Nie, H.-Y. Zhang, X.-H. Chen, New operators on triangular intuitionistic fuzzy numbers and their applications in system fault analysis, Inform. Sci., 251 (2013), 79-95. 1

[16] M.-M. Xia, Z.-S. Xu, Hesitant fuzzy information aggregation in decision making, Internat. J. Approx. Reason., 52 (2011), 395-407. 1, 2.1, 2.2, 2

[17] Z.-S. Xu, Some similarity measures of intuitionistic fuzzy sets and their applications to multiple attribute decision making, Fuzzy Optim. Decis. Mak., 6 (2007), 109-121. 1

[18] Z.-S. Xu, Q.-L. Da, The ordered weighted geometric averaging operators, Int. J. Intell. Syst., 17 (2002), 709-716. 1

[19] Z.-S. Xu, M.-M. Xia, Distance and similarity measures for hesitant fuzzy sets, Inform. Sci., 181 (2011), 2128-2138. 1, $2.3,2,4.4$

[20] R. R. Yager, On ordered weighted averaging aggregation operators in multicriteria decisionmaking, IEEE Trans. Systems Man Cybernet., 18 (1988), 183-190. 1

[21] L. A. Zadeh, Fuzzy sets, Information and Control, 8 (1965), 338-353. 1

[22] H.-M. Zhang, L.-Y. Yu, New distance measures between intuitionistic fuzzy sets and interval-valued fuzzy sets, Inform. Sci., 245 (2013), 181-196. 1

[23] X.-F. Zhao, R. Lin, G.-W. Wei, Hesitant triangular fuzzy information aggregation based on Einstein operations and their application to multiple attribute decision making, Expert Syst. Appl., 41 (2014), 1086-1094. 1 